\title{
Física Quântica na Escola Básica: investigações para a promoção de uma Aprendizagem Conceitual, Histórica e Epistemológica
}

Quantum Physics in Basic School: investigations for the promotion of Conceptual, Historical and Epistemological Learning

\author{
André Felipe Hoernig ${ }^{* 1 @}$, Neusa Teresinha Massoni ${ }^{1 @}$, Dimiter Hadjimichef ${ }^{2} @$ \\ ${ }^{1}$ Universidade Federal do Rio Grande do Sul, Instituto de Física, Programa de Pós-Graduação em Ensino de Física, \\ Porto Alegre, RS, Brasil. \\ ${ }^{2}$ Universidade Federal do Rio Grande do Sul, Instituto de Física, Programa de Pós-Graduação em Física, Porto Alegre, RS, \\ Brasil.
}

Recebido em 29 de janeiro de 2021. Aceito em 31 de março de 2021.

\begin{abstract}
O presente trabalho versa sobre possibilidades, tendências da literatura e estratégias didáticas para introduzir a Física Quântica no Ensino Médio, atentando para uma aprendizagem conceitual, visando conciliar História e Epistemologia com a aquisição de significados pelos educandos. Também buscamos trazer algum auxílio para professores, sobretudo quanto à escolha dos tópicos a serem ministrados, uma vez que não há total consenso na comunidade de Pesquisa em Ensino de Física quanto aos temas, a ordem, ou a forma como os diferentes assuntos desse campo podem ser ministrados. Nosso objetivo é apresentar algumas possibilidades para o Ensino de Física Quântica, através de um estudo teórico na forma de uma breve revisão da literatura e entrevistas curtas com professores especialistas, o que guiou o planejamento e execução de uma atividade prática na forma de um Módulo Didático. Concluímos que, dentro das diversas possibilidades quanto à execução de uma atividade didática, é possível um encaminhamento para uma aprendizagem mais conceitual, com a indicação de que alguns temas, como Interferência e Difração, são fundamentais e merecem grande atenção em uma unidade de ensino.

Palavras-chave: Física Quântica, Escola Básica, Epistemologia, Interferência, Difração.
\end{abstract}

The present work deals with possibilities, tendencies in literature and didactic strategies to introduce Quantum Physics in High School, paying attention to conceptual learning, aiming to reconcile History and Epistemology with the acquisition of meanings by students. We also seek to bring some help to teachers, especially regarding the choice of topics to be contemplated, since there is no total consensus in the Physics Teaching Research community regarding the subjects, the order, or the way the different topics in this area can be taught. Our goal is to present some possibilities for the Teaching of Quantum Physics, through a theoretical study in the form of a brief review of the literature and short interviews with specialist professors, which guided the planning and execution of a practical activity in the form of a Didactic Module. We conclude that, within the various possibilities regarding the execution of a didactic activity, it is possible work with a more conceptual learning, with the indication that some topics, such as Interference and Diffraction, are fundamental and deserve great attention in a teaching unit. Keywords: Quantum Physics, Basic School, Epistemology, Interference, Diffraction.

\section{Introdução}

Introduzir a Física Moderna Contemporânea (FMC) no Ensino Médio não é mais novidade na literatura da área de Pesquisa em Ensino de Física. Há décadas se discutem a necessidade, maneiras e possibilidades de se introduzir temas que marcaram os grandes desenvolvimentos do pensamento científico ocorridos a partir do início do século XX de forma adequada na Escola Básica [1, 2]. Dentre os diversos tópicos contemplados pelo "guardachuva" da FMC, a Física Quântica tem se mostrado como um conteúdo de importância indiscutível [3], por

\footnotetext{
*Endereço de correspondência: andre.hoernig@gmail.com
}

diferentes razões. Alguns pesquisadores defendem que para um conteúdo ter de fato importância indiscutível, é necessário que tenha legitimidade cultural ou social [4]. Defende-se que a Física Quântica dispõe de legitimidade cultural e social, dada sua contribuição para a formação cidadã em virtude de sua ampla aplicação em diversas tecnologias na forma de artefatos criados pelo ser humano [5]. Compreende-se também que possui grande legitimidade cultural, dada a grande influência em aspectos diversificados da cultura contemporânea, sobretudo na ficção científica e em obras diversas que utilizam a Quântica para divulgação científica. Temos como exemplo o trabalho de Park, Yang e Song [6], que utilizaram conceitos do filme Interestellar (2014) para 
a introdução de tópicos relacionados à FMC em uma unidade didática na Coréia do Sul. Hilger e Moreira [7], por outro lado, observaram que tamanha é a apropriação da ficção de termos do universo reificado científico, que interpretações errôneas da Física Quântica levam à formação de concepções místicas nos educandos, o que também é percebido em estudo por nós realizado [8], ao estudar as Representações Sociais 9 de alunos de Ensino Médio no que diz respeito à Quântica.

No presente trabalho, salientamos que conduzimos a pesquisa de forma a privilegiar uma aprendizagem que valorizasse o aspecto conceitual, visando promover certo grau de letramento científico e que expressasse a essência da Física Quântica em seu nível mais introdutório. Notase também que, apesar da destacada preocupação com o Ensino de FMC, particularmente de Física Quântica, poucos são os trabalhos que tratam deste com um viés que permita articular essa inserção com discussões sobre História e Epistemologia (ou Filosofia) da Ciência no Ensino Médio. Entendemos que a prática educativa precisa ser, além de efetiva do ponto de vista científico e didático, capaz de preparar o estudante para a vida em sociedade mais consciente e reflexiva, onde há o convívio com muitas formas distintas de pensamento. Para isso, o Ensino precisa ter, em algum grau, um viés mais humanista, que mostre a Ciência como uma construção feita por pessoas humanas, evidentemente com grande aptidão para a resolução de problemas tanto empíricomatemáticos como conceituais [10], mas destacando que são cientistas que têm diversas idiossincrasias como qualquer pessoa comum.

Identificamos que inúmeras propostas didáticas de Física não abordam os nomes de cientistas e pesquisadores que contribuíram de forma relevante para o desenvolvimento científico [11], o que classificamos como uma grande perda de potencial da prática didática, podendo inclusive passar uma imagem distorcida da Ciência, de que talvez a atividade científica não seja para todos [12]. Assim, é preciso mitigar essa limitação oferecendo alternativas com um apelo à abordagem Histórica e Epistemológica, uma vez que, ao abordarmos aspectos históricos do desenvolvimento da Física Quântica, foco do Módulo Didático (MD) aqui apresentado, é natural que sejam abordados aspectos da natureza da ciência e do fazer científico, pois como afirma Imre Lakatos, parafraseando Kant: "a filosofia da ciência sem a história da ciência é vazia; a história da ciência sem a filosofia da ciência é cega" [13, p. 107]. Em nosso MD, em resumo, buscamos abordar as importantes contribuições de Planck, Einstein, Dirac e outros, de forma a realizar um trabalho identificado na literatura como trabalho de fronteira [14, em que há um interesse primeiro pela apresentação do conteúdo Físico, mas com uma constante preocupação em evidenciar os contextos extraacadêmicos nos quais a Física esteve relacionada.

Um empecilho, contudo, que limita a execução de qualquer planejamento didático no que se refere à FMC é com certeza a falta de tempo 15, dado que é um assunto que costuma ser ministrado ao final do Ensino Médio, geralmente "quando sobra tempo", após ministração de conteúdos considerados mais urgentes na grade disciplinar. Com isso em mente, por mais que se queira seguir uma abordagem Histórica e Epistemológica, o professor pode se sentir com dificuldades sobre quais temas merecem mais atenção e como deve ministrálos, uma vez que também não há um consenso na comunidade de Pesquisa em Ensino quanto a isso, como aponta Cuesta-Beltrán [16]. Com essas preocupações em mente, procuramos propor caminhos no intuito de ajudar professores de Física e pesquisadores para ministração de um Módulo Didático de Física Quântica, sem renunciar à História e à Epistemologia da Ciência. Nas seções subsequentes apresentaremos os aspectos metodológicos e, depois, os resultados da revisão de literatura que buscou trazer um panorama das pesquisas que tratam de Ensino de Física Quântica para/no Ensino Médio; e de entrevistas com professores de Física universitários, visando trazer subsídios para a preparação de um MD 1 que foi aplicado ao final de 2019 em uma escola da rede pública estadual, no município de Gravataí, na região metropolitana de Porto Alegre e, por fim, trazemos algumas considerações finais e possibilidades para próximas pesquisas.

\section{Metodologia}

\subsection{Escopo da revisão de literatura}

Com a intenção de estabelecer uma revisão teórica que subsidiasse a investigação por nós conduzida, foi mapeada a produção acadêmica relativa ao Ensino de Física Quântica no Ensino Médio. Fizemos buscas por meio de descritores, apresentados a seguir, referentes a essas questões na plataforma Web of Science, sendo que optamos pela busca e revisão de artigos acadêmicos e artigos publicados em anais de eventos ou congressos, sem levar em conta dissertações e teses, em virtude do bom número de textos que foi obtido através da busca nessa base. Optamos por utilizar apenas descritores em inglês, dado que com eles foi localizado um bom número de artigos em língua portuguesa, uma vez que é comum que todo artigo também contenha título e resumo em inglês.

Utilizamos os descritores "Quantum Physics Teaching AND Secondary School" na base Web of Science Core Collection (a base Web of Science faz distinção entre os operadores booleanos AND, OR e NOT), acessível via portal de periódicos da Capes. Optamos por utilizar

\footnotetext{
1 Para não tornar este artigo demasiadamente longo, acreditamos não ser adequado trazer uma descrição detalhada do Módulo Didático, mas esta descrição é apresentada na Dissertação de Mestrado acadêmico do primeiro autor [8], disponível no endereço https://lume.ufrgs.br/handle/10183/211521 acessado em jan. 2021.
} 
apenas Secondary School e não outros termos, como High School, por exemplo, porque nosso foco se deu para o Ensino de Física Quântica para a Escola Básica, em um contexto de Ensino Médio, como já explicitado. Com uso do filtro temporal, restringimos a busca a produções feitas entre 2009 e 2019 e obtivemos 17 artigos. Foram, então, considerados apenas aqueles que versassem sobre tópicos introdutórios de Física Quântica para o Ensino Médio, o que resultou em 13 trabalhos. Contudo, a busca na coleção principal da Web of Science fornece apenas artigos em inglês, o que não nos trazia uma boa indicação sobre as pesquisas realizadas no Brasil e na América do Sul. Assim, foi realizada uma busca com os mesmos descritores e filtros na base Web of Science SciELO (SciELO Citation Index), onde foram encontrados mais seis textos. A busca foi realizada nos primeiros meses de 2020, dentro de um escopo de pesquisa da dissertação do primeiro autor. Para este artigo, contudo, optamos por também acrescer nossa busca de publicações de 2020. Desta forma, utilizando os mesmos descritores e selecionando apenas o ano de 2020, encontramos mais seis artigos na Web of Science Core Collection e cinco na Web of Science SciELO. Destes onze textos, apenas mais dois foram selecionados, os demais não foram utilizados por não tratarem do Ensino de Física Quântica para/no Ensino Médio (7), ou por serem trabalhos inacessíveis (2).

\subsection{Entrevistas semiestruturadas com professores de Física}

Dada a revisão de literatura, explicitamos uma etapa importante para a preparação e execução de nosso MD, que se refere a entrevistas com professores de Física da Universidade Federal do Rio Grande do Sul. Em virtude do interesse em ministrar tópicos iniciais de Física Quântica no Ensino Médio, e dado que este ainda é um tema que, apesar de incentivado, pouco chega de fato à escola básica, ficamos com os seguintes questionamentos: qual seria a melhor forma de ministrar esse tema? Quais tópicos deveriam ser ministrados? Observamos que, em certo sentido, essa também era uma preocupação de educadores americanos durante a década de 1950, embora naquele contexto a preocupação era em elaborar um currículo capaz de formar futuros cientistas. As questões, contudo, eram similares: quais deveriam ser os tópicos abordados e como decidir entre os diferentes tópicos, entre diversas outras preocupações. Um importante pesquisador em educação daquele período foi o norte-americano Jerome Bruner, que apontou diversas sugestões e práticas que poderiam ser seguidas para alcançar o objetivo que se queria à época, ou seja, a formação de cientistas para auxiliar no desenvolvimento científico e tecnológico do país durante o período da Guerra Fria.

O ponto principal por nós utilizado da teoria de ensino de Bruner, contida sobretudo na obra O Processo da Educação [17, é a atenção dada por ele para o currículo, e suas sugestões de como escolher e preparar temas a serem ensinados no Ensino Médio. Esclarecemos, entretanto, que nossa perspectiva quanto ao ensino de Física Quântica foi voltada para a formação de uma representação social contemporânea pelos alunos e que corresponda a um correto entendimento da Física Quântica e, de maneira geral, da Ciência. Desta forma, as sugestões de Bruner no âmbito de formação de cientistas foram tomadas tão somente como inspiração metodológica.

Bruner e colaboradores em Massachusetts alcançavam progressos sobre um programa de ensino de Física tido como ideal para o ensino secundário, com o objetivo de formar cientistas no âmbito da Guerra Fria, ao incluírem os esforços não só de autores de textos, produtores de filmes e educadores, mas também de pessoas que possuíam algum destaque no campo da Física teórica e experimental. Nesse sentido, é recomendado na obra de Bruner "discutir um modo de facilitar as relações entre os cientistas das universidades e os que ensinam nas escolas" [17, p. 18]. Assim, Bruner sugere que para a elaboração de um programa tido por ele como ideal, deveriam ser envolvidos, além de educadores e pessoas diretamente ligadas à Escola, também físicos de formação, especialistas com experiência em pesquisa em Física.

Nesse sentido, procuramos, durante o planejamento do MD, colocar em prática essa sugestão da teoria de ensino de Bruner. Embora o contexto atual seja muito distinto daquele que moveu Bruner, ele não se modificou no que diz respeito aos desafios de ensinar Física Quântica no nível secundário, e esta foi a razão principal pela qual procedemos de maneira semelhante a KrijtenburgLewerissa, Pol, Brinkman e van Joolingen [15], estudo que compõe nossa revisão, em que os autores realizaram um estudo denominado estudo Delphi, com quarenta e oito professores de diversas universidades holandesas. No estudo, os professores foram entrevistados e solicitados a indicar quais temas julgavam indispensáveis à sequência didática sobre Física Quântica para o Ensino Médio. Procedemos de maneira semelhante, com a utilização de entrevistas semiestruturadas realizadas com alguns professores do Instituto de Física da UFRGS.

Massoni e Moreira [18] destacam que em entrevistas semiestruturadas, as questões direcionadas ao público entrevistado são abertas e flexíveis, permitindo que os sujeitos verbalizem livremente seus pensamentos, tendências e reflexões sobre o tema focalizado. Nesta modalidade de entrevista - existem diversas outras modalidades - aquele que entrevista pode levantar novas questões de acordo com a dinâmica do diálogo, que acontece naturalmente. O roteiro da entrevista compõese de uma lista de tópicos selecionados e não de questões fechadas. Assim, os dados obtidos geralmente não possuem uma forma determinada e por essa razão exigem um pouco mais de esforço para interpretação do que 
os obtidos por questionários com perguntas fechadas. Em compensação, podem ser mais ricos e resultar em informações mais profundas, uma vez que a discussão, por ser livre, pode suscitar tópicos ou temas que não poderiam ser mencionados em uma entrevista rígida, fechada.

Desse modo, realizamos entrevistas semiestruturadas com sete professores de Física do Instituto de Física da UFRGS, que foram escolhidos por terem já ministrado alguma disciplina de Física Quântica na universidade, a nível introdutório ou avançado. Nas entrevistas buscamos respostas a uma pergunta norteadora para as discussões:

- Que tópicos e que sequência o senhor(a) considera de extrema importância para um módulo didático de FQ no EM?

As respostas foram diversificadas e coletadas com o auxílio de um diário de campo. As entrevistas tomaram rumos distintos, por vezes com sugestões de leituras, seja de livros ou de artigos, ora com sugestões de atividades experimentais, além, evidentemente, de sugestões diretamente relacionadas com a pergunta que guiou as discussões. Vale destacar que um dos professores entrevistados se envolveu e auxiliou muito ativamente neste estudo, com diversas sugestões e com encontros regulares para além do selecionado para a entrevista. Por esta razão, foi convidado para coorientar a pesquisa, o que conduziu para colaboração no presente artigo. Na organização e análise das respostas, foi feita uma listagem simples dos conceitos sugeridos pelos professores e também uma nuvem de palavras, realizada com o software IRAMuTeQ ${ }^{2}$ que permite fazer diferentes formas de análise textual, em que palavras ou expressões mais repetidas ao longo de um texto (em nosso caso da transcrição do diário de campo contendo as respostas) ficam em maior destaque na nuvem. Assim, transcrevendo as entrevistas em qualquer programa de edição de texto, seguindo o padrão aconselhado pelos manuais que acompanham o programa, o software analisa o texto e permite, então, a construção de uma nuvem de palavras, que auxilia na visualização dos termos mais relevantes arrolados nas entrevistas.

\section{Revisão da Literatura}

Como apontado, analisamos vinte e um artigos voltados para o Ensino de Física Quântica que, para uma melhor visualização, foram organizados no Quadro 1 (destacando o ano da publicação, os autores e o título).

\footnotetext{
2 IRaMuTeQ é um acrônimo para a expressão em francês $I n$ terface de $R$ pour les Analyses Multidimensionnelles de Textes et de Questionnaires, sendo um software livre ligado ao pacote estatístico da linguagem R. Sendo assim, para rodar o IRaMuTeQ é necessário instalar os pacotes de funções do R. Pode-se efetuar o download do primeiro no endereço http://www.iramuteq.org/ e do segundo em https://www.r-project.org/
}

Entre os artigos selecionados identificamos preocupações e pesquisas distintas. Alguns pesquisadores defendem a abordagem de temas que sejam relevantes aos alunos, em que seja possível mostrar aplicações práticas dos conteúdos de Física Quântica [19, 20, alguns autores defendem a utilização de experimentos em laboratório ou com materiais de baixo custo [19, 21, 22] ou com a utilização de softwares e simulações computacionais disponíveis na internet [20, 23]. Outros autores se preocupam em analisar como são as diretrizes e direcionamentos nessa área, em termos de currículos para a escola básica [24, a organização de livros didáticos [25], ou em ambos, através de revisões sistemáticas sobre esse tema [16, 26, 27]. Há trabalhos que realizaram entrevistas com professores acadêmicos, de Ensino Médio e em formação, para procurar mapear os assuntos que se revelam mais recorrentes em introduções a essa temática, bem como buscaram mapear a existência de falhas ou limitações conceituais na atividade didática [15, 19, 27. 28. Identificamos também alguns relatos de experiências didáticas com abordagens diversas, como descrições de atividades com o Interferômetro de Mach-Zender [5, 23], relatos de módulos didáticos baseados em experimentos de pensamento [29, 30], exposição de atividades baseadas em leitura de textos científicos ou de divulgação científica [31, 32, ou ainda, relatos de atividades experimentais [21, 21, 33, sobretudo com o uso de lasers.

Entre estes diversos autores, Stadermann, van den Berg e Goedhart 24] ressaltam a importância do Ensino de Física Quântica na Escola Básica, defendendo ser um tema de extrema importância para um entendimento inicial da visão de mundo científica contemporânea, e que os estudantes devem ter a chance de aprender assuntos mais recentes e não se limitar à física do século XIX. Neste sentido, Pagliarini e Almeida [32] destacam que, mesmo para alunos que não utilizarão diretamente os conhecimentos científicos em situações de sua vida acadêmica ou profissional, a presença de temas como a Física Quântica no currículo e discussões escolares é enriquecedora e, sob certas circunstâncias, necessária.

Outros entendem que para a introdução de um dado tópico ser, de fato, necessária na Escola Básica é preciso que o tema tenha legitimidade cultural ou social [4, ou seja, que provenha de questões levantadas pela sociedade, de forma que os jovens estudantes obtenham um mínimo de entendimento para lidar com tais questões. Sob esta perspectiva, acreditamos que a Quântica dispõe de legitimidade cultural e social, uma vez que boa parte da tecnologia atual se baseia diretamente ou indiretamente nela. Não obstante, segundo Otero, Fanaro e Arlego 44, a Mecânica Quântica se mostra como a base da eletrônica de semicondutores, lasers, tecnologias nucleares e desempenha papel central no desenvolvimento de tecnologias recentes, como a computação quântica e diversos aspectos da nanotecnologia. Scholz, Wessnigk e Weber [5] argumentam nesta mesma linha, em que trazem um site da iniciativa europeia European Quantum 
Quadro 1: Listagem de artigos sobre Ensino de Física Quântica no Ensino Médio.

\begin{tabular}{|c|c|c|c|}
\hline & & & no de Física Quântica \\
\hline & Ano & Autores & Título \\
\hline 1 & 2020 & SCHOLZ; WESSNIGK; WEBER & A classical to quantum transition via key experiments \\
\hline 2 & 2020 & $\begin{array}{l}\text { IVANJEK; SHAFFER; } \\
\text { PLANINIĆ; MCDERMOTT }\end{array}$ & $\begin{array}{l}\text { Probing student understanding of spectra through the use of a typical } \\
\text { experiment used in teaching introductory modern physics }\end{array}$ \\
\hline 3 & 2019 & $\begin{array}{l}\text { KRIJTENBURG-LEWERISSA; } \\
\text { POL; BRINKMAN; VAN } \\
\text { JOOLINGEN }\end{array}$ & $\begin{array}{l}\text { Key topics for quantum mechanics at secondary schools: a Delphi study } \\
\text { into expert opinions }\end{array}$ \\
\hline 4 & 2019 & $\begin{array}{l}\text { STADERMANN; VAN DEN } \\
\text { BERG; GOEDHART }\end{array}$ & $\begin{array}{l}\text { Analysis of secondary school quantum physics curricula of } 15 \text { different } \\
\text { countries: Different perspectives on a challenging topic }\end{array}$ \\
\hline 5 & 2019 & CLAVIJO; WALTEROS; CORTÉS & $\begin{array}{l}\text { La actividad experimental como una parte fundamental para la } \\
\text { enseñanza de la física moderna: el caso de la mecánica cuántica. }\end{array}$ \\
\hline 6 & 2018 & $\begin{array}{l}\text { AYENE; KRICK; DAMITIE; } \\
\text { INGERMAN; THACKER }\end{array}$ & $\begin{array}{l}\text { A Holistic Picture of Physics Student Conceptions of Energy } \\
\text { Quantization, the Photon Concept, and Light Quanta Interference }\end{array}$ \\
\hline 7 & 2018 & FANARO; ELGUE & $\begin{array}{l}\text { La Conceptualización De La Experiencia De La Doble Rendija A Partir } \\
\text { Del Enfoque De Caminos Múltiples de Feynman }\end{array}$ \\
\hline 8 & 2018 & CUESTA-BELTRÁN & $\begin{array}{l}\text { Estado del arte: tendencias en la enseñanza de la física cuántica entre } \\
1986 \text { y } 2016\end{array}$ \\
\hline 9 & 2017 & $\begin{array}{l}\text { KRIJTENBURG-LEWERISSA; } \\
\text { POL; BRINKMAN; VAN } \\
\text { JOOLINGEN }\end{array}$ & $\begin{array}{l}\text { Insights into teaching quantum mechanics in secondary and lower } \\
\text { undergraduate education }\end{array}$ \\
\hline 10 & 2017 & MARKIN; MARKINA; EILKSB & $\begin{array}{l}\text { The application of laser pointers for demonstration experiments in } \\
\text { nanotechnology lessons at secondary school level }\end{array}$ \\
\hline 11 & 2016 & PAGLIARINI; ALMEIDA & $\begin{array}{l}\text { Leituras por alunos do ensino médio de textos de cientistas sobre o } \\
\text { início da física quântica }\end{array}$ \\
\hline 12 & 2015 & $\begin{array}{l}\text { HERAUD; LAUTESSE; FERLIN; } \\
\text { CHABOT }\end{array}$ & $\begin{array}{l}\text { Representing the Quantum Object Through Fiction in Teaching. The } \\
\text { Ontological Contribution of Gamow's Narrative as Part of an } \\
\text { Introduction to Quantum Physics }\end{array}$ \\
\hline 13 & 2015 & $\begin{array}{l}\text { LAUTESSE; VALLS; FERLIN; } \\
\text { HERAUD; CHABOT }\end{array}$ & $\begin{array}{l}\text { Teaching Quantum Physics in Upper Secondary School in France: } \\
\text { 'Quanton' Versus 'Wave-Particle' Duality, Two Approaches of the } \\
\text { Problem of Reference }\end{array}$ \\
\hline 14 & 2014 & ASIKAINEN; HIRVONEN & $\begin{array}{l}\text { Probing Pre-and In-service Physics Teachers' Knowledge Using the } \\
\text { Double-Slit Thought Experiment }\end{array}$ \\
\hline 15 & 2013 & LEVRINI; FANTINI & $\begin{array}{l}\text { Encountering Productive Forms of Complexity in Learning Modern } \\
\text { Physics }\end{array}$ \\
\hline 16 & 2013 & BERTOZZI & $\begin{array}{l}\text { What is what we call the 'quantum field'? Answering from a teaching } \\
\text { perspective by taking the foundations into account. }\end{array}$ \\
\hline 17 & 2013 & $\begin{array}{l}\text { ALEMANY; BLANCO; } \\
\text { TORREGROSA }\end{array}$ & La introducción del concepto de fotón en bachillerato \\
\hline 18 & 2011 & VELENTZAS; HALKIA & $\begin{array}{l}\text { The 'Heisenberg's Microscope' as an Example of Using Thought } \\
\text { Experiments in Teaching Physics Theories to Students of the Upper } \\
\text { Secondary School }\end{array}$ \\
\hline 19 & 2010 & $\begin{array}{l}\text { STEVENS; DELGADO; } \\
\text { KRAJCIK }\end{array}$ & $\begin{array}{l}\text { Developing a Hypothetical Multi-Dimensional Learning Progression for } \\
\text { the Nature of Matter }\end{array}$ \\
\hline 20 & 2009 & BETZ; LIMA; MUSSATTO & $\begin{array}{l}\text { Dualidade onda-partícula: um objeto de aprendizagem baseado no } \\
\text { interferômetro de Mach-Zehnder }\end{array}$ \\
\hline 21 & 2009 & OTERO; FANARO; ARLEGO & $\begin{array}{l}\text { Investigación y desarrollo de propuestas didácticas para la enseñanza de } \\
\text { la Física en la Escuela Secundaria: Nociones Cuánticas }\end{array}$ \\
\hline
\end{tabular}

Fonte: Elaborado pelo primeiro autor (2021).

Flagship ${ }^{3}$ que se destaca pelo jargão "The Future is Quantum", em que é apresentado o que é denominada de segunda revolução quântica, oriunda de uma ampla variedade de aplicações da nova Física Quântica.

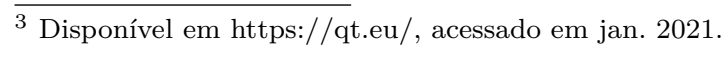

Não obstante, a temática também tem relevância cultural pelo fascínio, com um apelo muitas vezes místico no público em geral, relevado pela ficção e pelo entendimento popular de tópicos como teletransporte, universos paralelos ou computadores quânticos [24]. Também é destacado que o entendimento público da ciência, 
sobretudo da Física Quântica, torna o papel do professor uma tarefa complicada, sobre a qual é necessário lançar um olhar mais cuidadoso, para que se transmita uma visão correta da ciência.

Stadermann, van den Berg e Goerdhart 24 salientam que o ensino de Física Quântica, entre diversas possibilidades, propicia situações de discussão sobre a filosofia e natureza da ciência, uma vez que oferece novas visões de realidade e interpretações que entram em conflito com conceitos anteriormente aprendidos na Física Clássica como a natureza das partículas, localidade e determinismo. Os autores destacam que não se deve apresentar a Física como apenas baseada em fatos e que, por isso, necessariamente seria verdadeira, uma vez que o aluno que entende que a ciência fornece uma verdade absoluta, entre diversos problemas de ordem histórica e epistemológica, encontrará dificuldades para lidar com as diferentes interpretações da Física Quântica, as quais revelam diferentes visões sobre a natureza dos entes quânticos, nenhuma sendo mais ou menos verdadeira. Ressaltam que, na prática, muitos estudantes conhecerão apenas uma interpretação, a interpretação favorita do professor, ou mesmo do livro didático adotado por ele.

Betz, Lima e Mussato [23] destacam que uma interpretação pode ser informalmente definida como uma ponte conceitual que é estabelecida entre os elementos da teoria e os fatos experimentais, sendo que existem diversas interpretações compatíveis com os dados e internamente consistentes, porém com diversas divergências conceituais entre elas. Os autores relatam que em sua atividade didática optaram pela escolha da interpretação de Copenhague, ou de Bohr e von Neumann, mas mencionam interpretações alternativas, como a interpretação dos muitos universos ou do estado relativo, a interpretação da onda piloto ou das variáveis ocultas. Stadermann, van den Berg e Goerdhart [24] sublinham que é de fundamental importância evidenciar a existência de diversas interpretações para um mesmo fato, amenizando a ideia de ciência como fornecedora de uma verdade absoluta. Betz, Lima e Mussato [23] destacam ainda a importância de atividades computacionais e simulações, pois permitem uma melhor visualização de diversos fenômenos quânticos, visão corroborada por Otero, Fanaro e Arlego 44 e Stevens, Delgado e Krajcik 20].

Contudo, a visualização de tais fenômenos quânticos pode ser problemática ao ensino. Levrini e Fantini [34], ao analisarem uma série de livros-texto de Física utilizados em escolas italianas, destacam que o desejo de simplificar o conteúdo, com o uso de analogias e representações visuais na tentativa de torná-lo o mais próximo possível da linguagem dos alunos pode ser perigoso, uma vez que se corre o risco de distorcer o conteúdo, bem como o processo de aprendizagem. Destacam, por exemplo, que os alunos encontram grande dificuldade em assimilar a noção de dualidade ondapartícula, pois "negam que o que geralmente é pensado como uma partícula possa se comportar como uma onda. Eles veem isso como algo que pode ser dividido em dois, mas deve estar 'aqui' ou 'lá'." [34, p. 3, tradução nossa]. Segundo estes autores, a necessidade de comparação com o mundo clássico deve atenuar-se, uma vez que a Física Quântica e sua nova descrição matemática projeta o mundo real em um espaço abstrato e não familiar, como o espaço de Minkowski ou o espaço de Hilbert. Estes espaços abstratos, destacam eles, são "construções intelectuais que não podem ser relacionadas com o "espaço do mundo real' de modo intuitivo" [34, p. 4, tradução nossa], enfatizando que em intervenções didáticas é recomendado ao professor alertar que se está adentrando em um campo de estudo completamente novo, onde nossos conceitos mais fundamentais de tempo, espaço e localidade são profundamente modificados e que novos conceitos, não concebidos na Física Clássica, são agora criados. Alertam ainda que é preciso que haja a aceitação de que a Mecânica Quântica requer uma quantidade mínima, ou nenhuma, de visualizações por meio de imagens familiares, como um modelo planetário.

Nesse sentido, Standermann, van den Berg e Goedhart 24 destacam que certos tópicos apresentados em cursos introdutórios de Quântica carregam o problema da visualização; tópicos como linhas espectrais de gases, níveis de energia discretos em átomos e diodos emissores de luz (LEDs) estão relacionados à Quântica, mas podem ser perfeitamente entendidos com o modelo planetário semiclássico de Bohr. Portanto, não seriam tópicos que exprimem a essência da Física Quântica, como a dualidade ou o caráter probabilístico, e não deveriam constar em um curso de Mecânica Quântica. Estes autores recomendam, então, o uso do termo "Física Quântica", ao invés de "Mecânica Quântica", uma vez que o foco da ministração seria apresentar algumas ideias centrais, os principais cientistas e aplicações tecnológicas. Levrini e Fantini [34] apontam que o recurso da visualização deve ou ser evitado, ou quando for muito necessário, que seja feito com muito cuidado. Defendem que se utilize em primeiro lugar representações gráficas que facilitem o entendimento das ideias matemáticas, no que chamam de "visibilidade" (visualizability, ou Anschaulichkeit, termo recorrente no alemão) ao invés da visualização (visualization, ou Anschauung).

Um exemplo de recurso que permite a visualização são os diagramas de Feynman. Identifica-se que a técnica de diagramas de Feynman tem recebido grande importância em atividades com turmas de Ensino Médio, sendo que todos são utilizados para entendimento do experimento de dupla-fenda. Betz, Lima e Mussato [23] enfatizam que o experimento de dupla-fenda é um quadro canônico para a apresentação da dualidade e a análise das questões associadas. Otero, Fanaro e Arlego 4 destacam que as propostas baseadas no enfoque de Feynman utilizam a técnica de caminhos múltiplos, se centrando no comportamento da luz e fazendo grande uso de ferramentas 


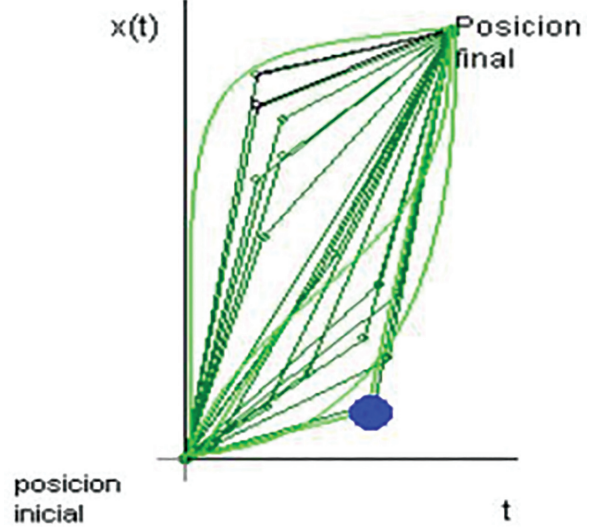

Figura 1: llustrando a técnica de múltiplos caminhos de Feynman [4].

computacionais. Esta proposta é ilustrada na imagem da Figura 1. onde Otero, Fanaro e Arlego 4 procuram sintetizar a técnica dos caminhos múltiplos utilizando o software "Modellus" 4

Em resumo, se consideram todos os caminhos que conectam o estado inicial $I(0,0)$ ao estado final $F(x, t)$. A cada $x(t)$ possível se associa um valor numérico chamado ação $S$, relacionado à energia cinética média temporal $E_{C P}$ e ao potencial médio temporal $E_{P P}$. A partir de $S$ se constrói um vetor denominado "amplitude de probabilidade" associado a cada $x(t)$; se adicionam todos os vetores associados aos diferentes caminhos que conectam os estados inicial e final, chamando esse vetor resultante de soma de "amplitude total de probabilidade"; calcula-se o módulo deste e o resultado é a probabilidade de chegar ao estado final $F$, partindo do estado inicial $I$.

Quanto ao aporte teórico-didático, Otero, Fanaro e Arlego 44 utilizaram a Teoria dos Campos Conceituais de Vergnaud, destacando que a Mecânica Quântica é entendida como um campo conceitual, em que os educadores procuram reconstruir no ambiente escolar o campo conceitual estabelecido na academia, sendo esta relação entre escola e universidade denominada de Estrutura Conceitual de Referência (ECR). Mais precisamente, uma estrutura conceitual de referência é:

um conjunto de conceitos, relações entre eles, princípios, declarações de conhecimento e explicações relacionadas a um determinado CC [campo conceitual], reconstruído pelo pesquisador de acordo com o conhecimento produzido pela comunidade científica de referência [4, p. 63, tradução nossa].

\footnotetext{
4 O Modellus é um software gratuito para modelagem interativa com matemática. Pode-se usá-lo para construir modelos matemáticos e explorá-los com animações, gráficos e tabelas. O Modellus é um software antigo e seu site oficial encontra-se desativado. Contudo, pode ser encontrado em http://www.fisica. ufpb.br/ romero/port/modellus.htm acessado em jan. 2021.
}

Com a Estrutura Conceitual de Referência em mente, que pode ser obtida através de diversas formas, como o contato direto com professores [26], ou por manuais didáticos diversos e livros-textos, sempre de maneira crítica e reflexiva 31, passa-se à construção de uma Estrutura Conceitual Proposta para Ensinar (ECPE), que se assemelha à ECR, porém com objetivo de transformar esta em uma estrutura acessível ao aluno, com base no contexto da instituição de aplicação. As situações, um conceito chave na teoria de Vergnaud [35], são entendidas nesses trabalhos como aquilo que subsidia e fundamenta a montagem da ECPE com base na ECR. Desta forma, Otero, Fanaro e Arlego [4, p. 63, tradução nossa], conforme ilustrado na Figura 2 sintetizam que:
Ao propor uma ECPE, se projeta e se ana- lisa didaticamente o conjunto de situações que permitirão o surgimento e operação dos conceitos-chave, os princípios-chave da ECPE correspondentes, as perguntas-chave, as explicações e afirmações de conhecimento que se espera que sejam realizadas, emoções e ações, sentimentos, mecanismos explicati- vos e linguagem na qual serão formuladas explicações e afirmações de conhecimento.

Destaca-se que dentro do grande tema da Mecânica Quântica existem diversas possíveis ECR, que se referem aos diferentes tópicos que o professor venha a trabalhar, neste caso, a experiência de dupla fenda. Para cada ECR, existem diferentes possibilidades de ECPE, ou seja, existem diferentes formas de ensinar um mesmo tópico; uma delas é a técnica de caminhos múltiplos de Feynman. Os autores sintetizam a ECR que guia a formação da ECPE em um mapa, apresentado na Figura 3 que achamos relevante mostrar (destaca-se que $\eta$ é a forma que os autores utilizam para representar a constante de Planck reduzida).

Propostas como esta enfatizam a descrição probabilística como um aspecto central da teoria Quântica, onde se constrói uma simulação na qual a construção do gráfico da função probabilidade é mostrada para cada valor de $x$, e simultaneamente os dois principais vetores que contribuem para o cálculo da probabilidade são desenhados, para cada fenda. Na Figura 4 . são apresentadas algumas das telas oferecidas pela simulação.

Desta forma, essas propostas amenizam o problema da visualização destacado por Levrini e Fantini 34. diante da dificuldade de se trabalhar com a ontologia dos entes quânticos. Asikainen e Hirvonen [29] também tomaram como objeto de estudo o experimento de dupla fenda. Todavia, procurando mapear o entendimento de professores de física de escolas da Finlândia, professores atuando ou em processo final de formação acadêmica, sobre o experimento de dupla-fenda como um experimento de pensamento (portanto, sem o uso de simulações computacionais). Apesar do recorrente uso e defesa dos experimentos de pensamento [30], os autores salientam que estes devem se constituir uma ferramenta 


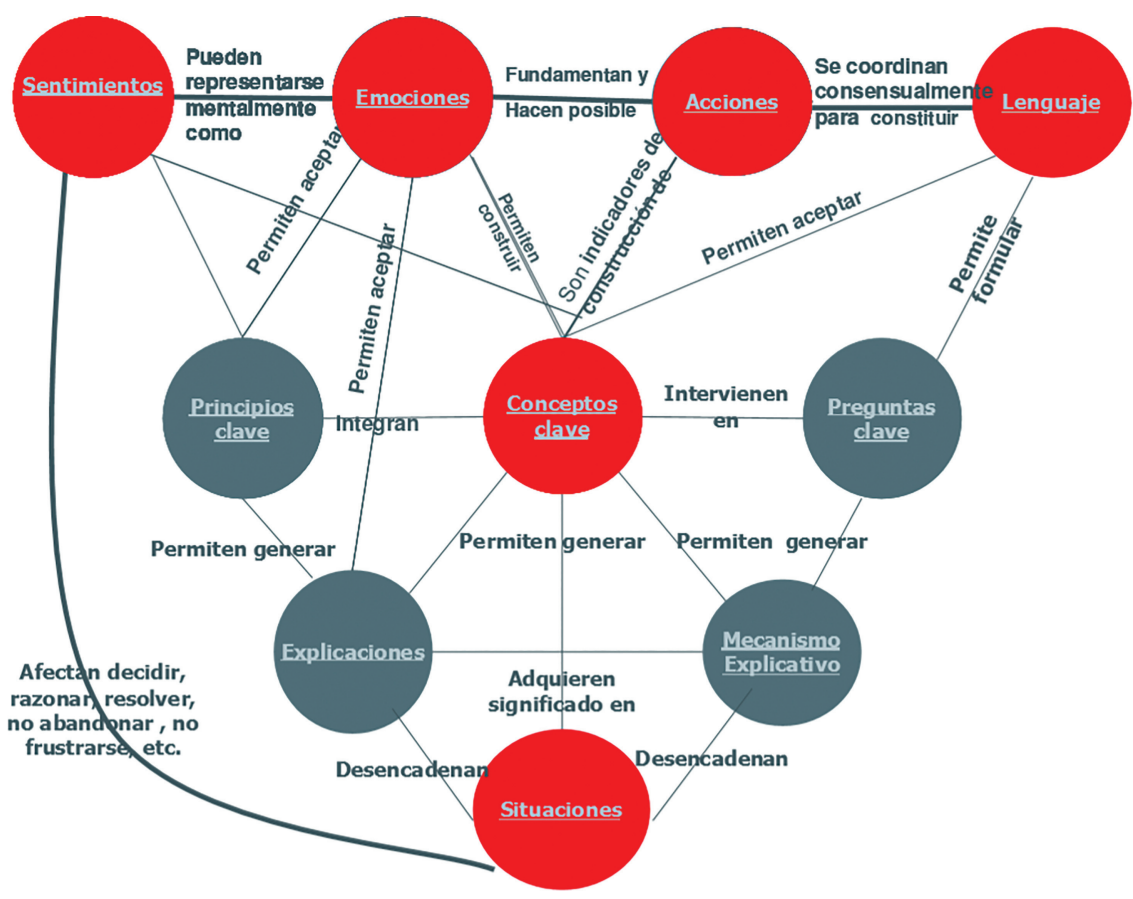

Figura 2: Os elementos que compões a Estrutura Conceitual Proposta para Ensinar [4].

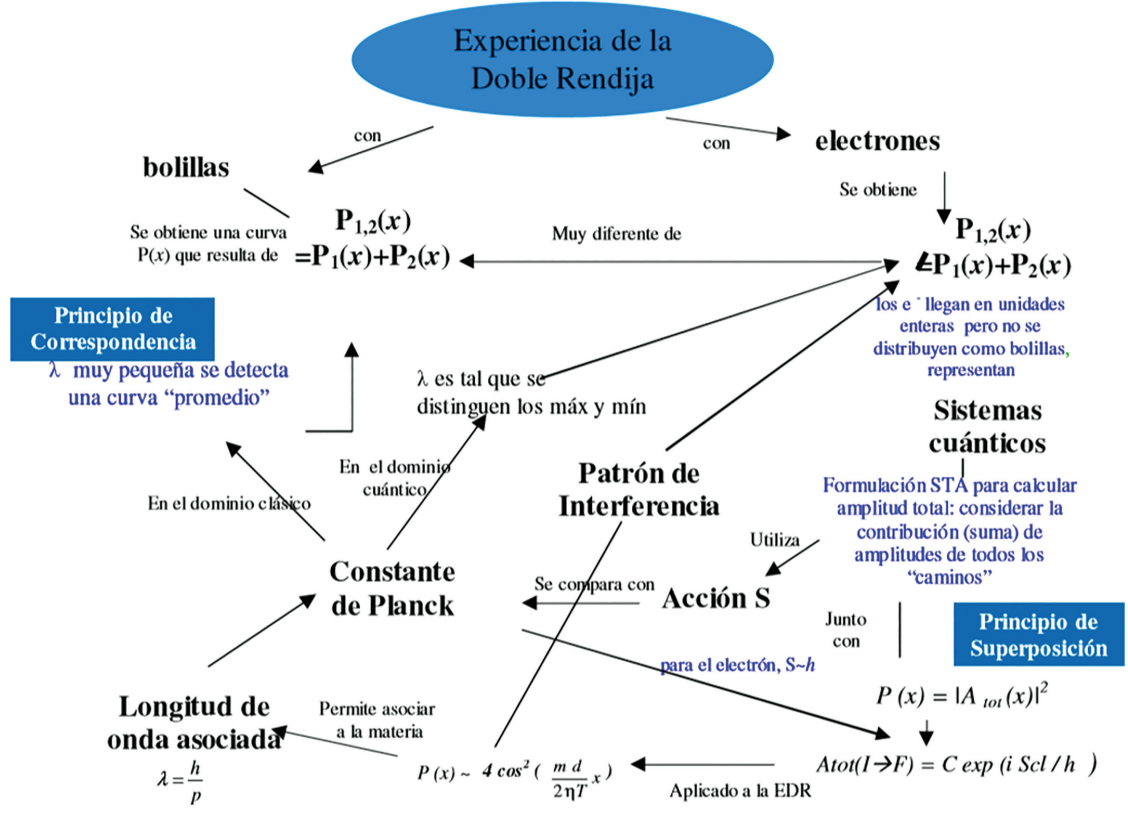

Figura 3: Estrutura Conceitual de Referência [4].

auxiliar e não como técnica frequente que subsidie por completo uma intervenção didática, uma vez que este "nunca pode substituir observações ou um experimento físico, porque um experimento de pensamento repousa em pressupostos auxiliares considerados verdadeiros" [28, p. 2, tradução nossa].

Os autores solicitaram aos professores que desenhassem como seria o padrão registrado em um anteparo, após luz e elétrons terem passado por um sistema de fenda dupla. Destacam que para o padrão de inter- ferência poder surgir, algumas premissas devem ser consideradas: para a luz basta que as fendas tenham tamanho de cerca de $0.1 \mathrm{~mm}$ e que a distância entre elas seja de $0.5 \mathrm{~mm}$; já para elétrons, a largura das fendas deve ser menor que o comprimento de onda de De Broglie, $\lambda=h / p$. O experimento de dupla-fenda como um experimento de pensamento necessita estar fundamentado neste conjunto de premissas. Os pesquisadores destacam que todas as respostas levantadas junto aos professores apontam que as fendas necessitam ter largura menor ou 

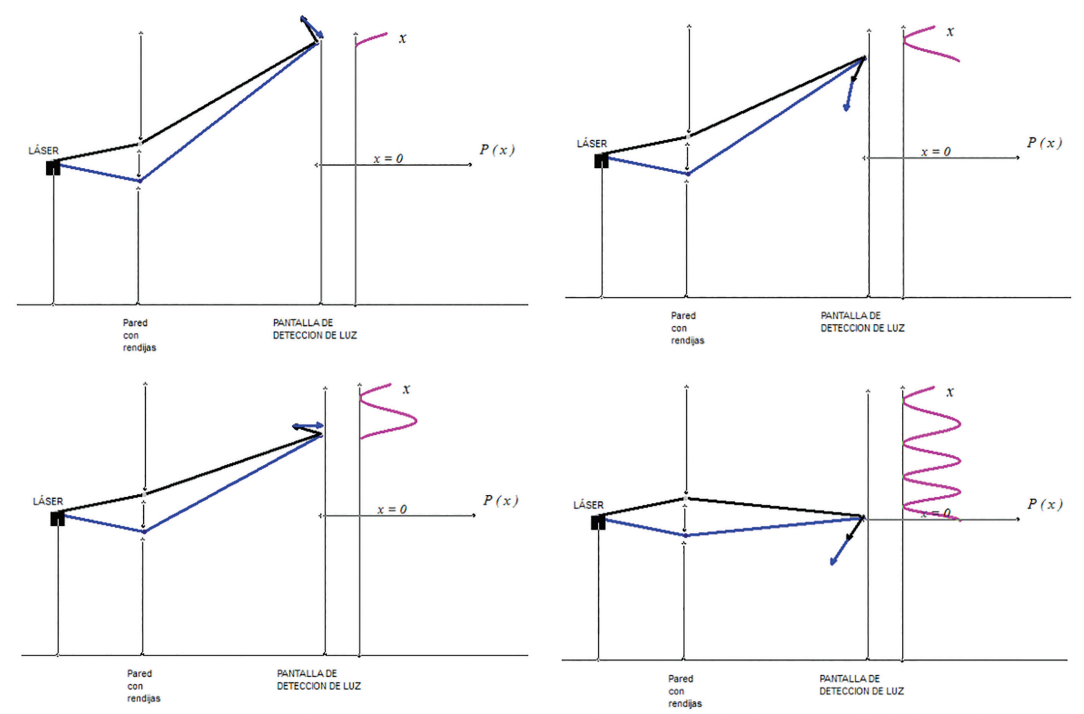

Figura 4: Algumas telas de saída da simulação para Experiência de Dupla Fenda com enfoque em caminhos múltiplos de Feynman [29].

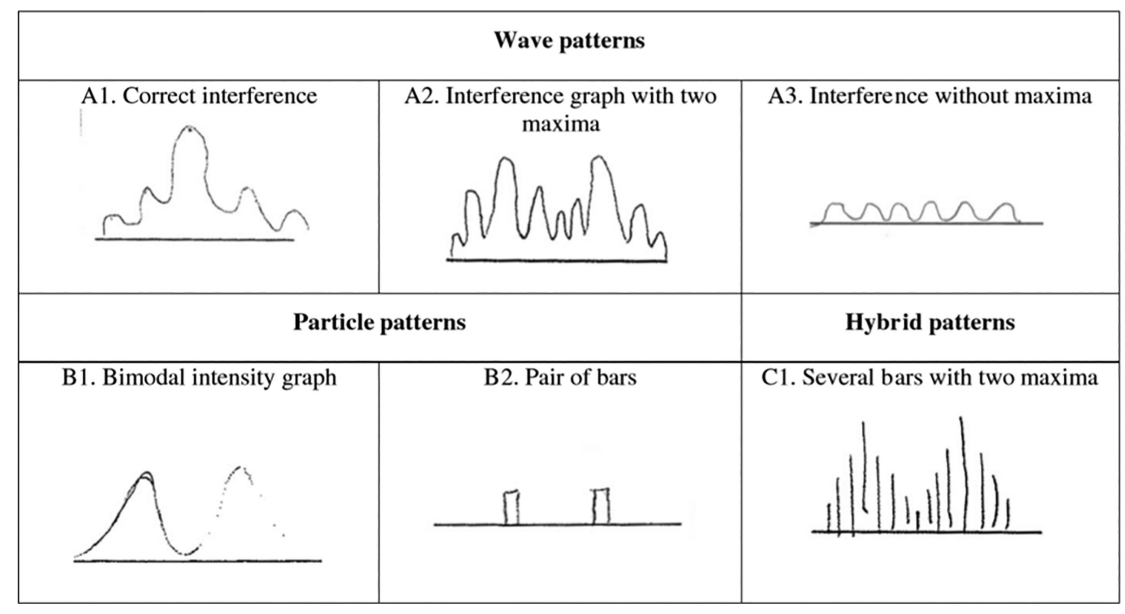

Figura 5: Os diferentes padrões de interferência destacados pelos professores [28].

igual ao comprimento de onda da luz, porém "se a fenda for menor que, por exemplo, $500 \mathrm{~nm}$, a intensidade seria tão pequena que o padrão de intensidade não seria visível ao olho humano" [28, p. 10, tradução nossa]. Contudo, destacam que mesmo com pressupostos errados, alguns professores chegaram ao padrão esperado para o experimento, porém diversos docentes, sobretudo professores ainda em formação, destacaram padrões de interferência destoantes do esperado para este experimento de pensamento. Alguns resultados obtidos pelos autores foram classificados e são ilustrados na imagem da Figura 5.

Destacaram que os participantes do estudo tinham a tendência de caracterizar elétrons dentro da categoria de partículas clássicas ao invés da categoria de entes quânticos. Sugerem que tal dificuldade é causada por ensinos tradicionais, os quais:

usam análogos mecânicos sem discriminar entre os diferentes status ontológicos dos conceitos que levarão os alunos a tratar partículas elementares como objetos materiais comuns [28, p. 19, tradução nossa].

Desta forma, é evidenciado novamente o problema de visualização, que se refere ao caráter ontológico dos entes quânticos, e a dificuldades de alunos e, também de professores, como destacado pelos autores, em assimilar esse caráter. Outrossim, Cuesta-Beltrán [16] destaca o grande número de professores em formação que apresentam falhas no entendimento de aspectos conceituais fundamentais da teoria, erros que persistem mesmo após o término do curso. Os futuros professores "confundem as ideias clássicas com as quânticas em situações próprias da Física Quântica e esses erros provavelmente se propagam aos seus alunos e aos livros por eles escritos" [16, p. 152, tradução nossa].

Novamente quanto ao caráter ontológico dos entes quânticos, Lautesse, Valls, Ferlin, Héraud e Chabot 36 
enfatizam que a dualidade onda-partícula é uma formulação que se aplica à manifestação de fótons ou elétrons, que se comportam como onda ou partícula dependendo do experimento considerado. Todavia, a dualidade não descreve a natureza intrínseca de fótons e elétrons, que não são ondas ou partículas, mas entes quânticos, certas vezes denominados quantons [36]. Esta denominação, conforme destacado pelos autores, foi elucidada no final da década de sessenta pelo filósofo da ciência Mario Bunge, na tentativa de afastar a quântica das analogias clássicas. O quanton é um termo próprio para designar todos os entes quânticos, que não são ondas nem partículas; são elementos que não podem ser identificados visualmente, mas que são reais e obedecem às leis da Mecânica Quântica, de forma a fornecer uma interpretação realista e literal que é negada pela interpretação de Copenhague.

Em uma análise de currículos de quinze países Europeus foi identificado que o currículo francês utiliza em suas diretrizes o termo quanton, e esta noção já vem sendo empregada em diversos livros-texto do país [24. Além disso, salientam estes autores que, apesar da comunidade de pesquisadores de ensino de ciências apontar que aspectos da Epistemologia e História da Ciência auxiliam na construção do conhecimento físico, os currículos europeus demonstram pouca ou nenhuma preocupação em trazer indicações sobre a temática. Identificaram também que, em se tratando do ensino de Física Moderna, apenas Noruega e Suécia possuem indicações para tratar os aspectos NOS (Nature of Science) e filosofia da ciência no contexto da sala de aula, mas apenas de forma indireta. Indicam que esta falta de preocupação em nível curricular tem uma influência negativa direta na sala de aula, uma vez que os livros didáticos, para serem aprovados, necessitam estar baseados nas diretrizes curriculares. Desta forma, o aspecto histórico é relegado, ou algumas vezes abordado de forma equivocada. As situações mais destacadas são referentes ao surgimento da teoria quântica com Planck e Einstein, em que se apresenta a situação do surgimento da teoria quântica como sendo um evento aguardado pela comunidade científica, com ampla e rápida aceitação. Nesse sentido, colocam que

\section{A maioria dos livros didáticos simplifica o curso real da história, apresentando o efeito fotoelétrico como um problema não resolvido que foi brilhantemente explicado por Eins- tein e, consequentemente, levou à introdução e aceitação da nova teoria quântica [24, p. 13, tradução nossa].}

Salientam ainda que essa práxis não corresponde com o real desenvolvimento da Quântica, classificando a abordagem como quase-histórica, com experimentos e descobertas históricas sendo apresentados como se a ordem cronológica de evidências e falhas da física clássica tivesse tornado necessário o desenvolvimento de uma nova teoria.
Neste mesmo sentido, Alemany, Blanco e Torregrosa [25] identificaram que os livros texto utilizados na Espanha apresentam erroneamente a introdução do conceito de fóton. Em primeiro lugar, destacam que a teoria clássica em momento algum tornou necessário o desenvolvimento de uma nova teoria, pois a comunidade científica considerava que na física haveria apenas alguns aspectos a serem resolvidos, como as declarações de lorde Kelvin, de que a física acabou e que "as gerações seguintes de físicos só precisam melhorar os dispositivos experimentais e colocar decimais nos resultados" [25. p. 8, tradução nossa]. Essa visão da ciência se mostrava comum nos primeiros anos do século XX e influenciou a concepção de Planck, que em momento algum desejava propor uma nova teoria, pelo contrário:

A introdução do quantum de energia para explicar o espectro do corpo negro foi, [...], um recurso matemático que explicava os resultados experimentais, mas não modificava o modelo de radiação aceito até o momento [25, p. 5, tradução nossa].

Em seguida, enfatizam que na explicação para o Efeito Fotoelétrico, em 1905, Einstein considera o quantum como um pacote de energia sem uma imagem clara da natureza destes pacotes, o termo fóton não fora sugerido por ele. Ademais, apesar da capacidade explicativa das ideias manifestas por Einstein no artigo de 1905, a comunidade científica recebeu essa proposta com incredulidade e ceticismo, com aceitação apenas a partir de 1915 após o trabalho rigoroso de Millikan, que, visando "reafirmar a natureza ondulatória da luz, demonstrou a validade da equação proposta por Einstein ( $E=h \nu-W$ em notação moderna)" [25, p. 6, tradução nossa]. Assim, enfatizam que se por anos se negou o comportamento dual da luz e que se isto aconteceu com cientistas de grande relevância na comunidade científica, não se deve supor que alunos de Ensino Médio aceitem essa ideia imediatamente. O complexo contexto histórico de aceitação dos primórdios da teoria quântica pode auxiliar neste sentido, facilitando a aquisição de conceitos fundamentais.

Pagliarini e Almeida [32] constatam que a leitura de textos de divulgação científica e de originais de cientistas não é uma prática comum nas atividades escolares e que o conteúdo que chega aos alunos, baseado em livros didáticos diversos, acaba sendo distorcido, sobretudo no seu caráter histórico. Os autores afirmam que há uma diversidade para abordagens histórico-filosóficas da ciência, não apenas a tradicional técnica excessivamente matemática que torna as aulas extremamente desinteressantes aos alunos de Ensino Médio. O "desafio de tornar a MQ [Mecânica Quântica] interessante, efetiva e relevante para estudantes de Física é uma preocupação universal que não conhece fronteiras" [19, p. 2, tradução nossa]. Pagliarini e Almeida 32, em atividades didáticas com turmas brasileiras de Ensino Médio, salientam que a utilização de livros com linguagem mais acessível 
aos alunos, como por exemplo a autobiografia de Max Planck, com uma linguagem textual muitas vezes narrativa, ajudou a despertar o interesse dos alunos, bem como auxiliou na aquisição de novos conceitos. Os autores colocam que os alunos associavam as aulas de Física a fórmulas e a pouco ou nenhum conteúdo, e que a leitura possibilitou formular sentidos sobre a ciência.

De forma semelhante, Héraud, Lautesse, Ferlin e Chabot 31 consideram o uso de textos de divulgação científica como uma abordagem possível para estudos sobre epistemologia da Física, de maneira a despertar o interesse dos alunos e apresentar o conteúdo com uma linguagem mais acessível, sem cometer equívocos conceituais. Eles defendem que as narrativas escritas por George Gamow em Mr. Tompkins in Paperback de 1965 e The New World of Mr. Tompkins de 1999 constituem uma possibilidade viável para este objetivo, além de que trechos de obras de Gamow têm sido inseridas em diversos livros didáticos, principalmente na França. As histórias relatam as experiências de um personagem denominado Sr. Tompkins, que após assistir diversas conferências científicas sobre Física Moderna, em sonhos adentra em um universo em que uma única característica foi alterada: a constante de Planck teve seu valor imensamente aumentado. Um exemplo marcante da obra, que os autores relatam ter tido uma boa aceitação pelos alunos em uma escola francesa, referese a um trecho em que o Sr. Tompkins, um professor de física e um caçador visitam uma "selva quântica", onde se lê:

Esses três personagens estão montados nas costas de um elefante. De repente, eles são atacados por um bando de tigres. $\mathrm{O}$ caçador e o professor querem atirar nos tigres e o professor grita: "Espalhem o fogo por toda parte e não se importem com a mira precisa". Depois de muitos tiros, o bando de tigres de repente se torna um único tigre morto [31, p. 308, tradução nossa].

Desta forma, algumas ideias importantes da quântica são ilustradas de maneira clara e de fácil entendimento. O bando de tigres retrata a probabilidade de presença de um determinado tigre "distribuído" em uma ampla área. Em contraste, o tigre morto é equivalente ao "colapso de função de onda", com o tigre morto sendo então localizado em um local específico no espaço. Por fim, os autores defendem que a inserção, em sala de aula, de narrativas fictícias escritas por físicos permite um enriquecimento das reflexões dos estudantes sobre o conhecimento científico no mundo, facilitando de maneira didática a aquisição de conceitos referentes a diversos tópicos de Física Moderna, com as analogias fazendo sentido, uma vez que não há a limitação ontológica para esses exemplos fictícios, não é necessário a evocação de novos termos, como quanton [36], apenas tendo o cuidado de ressaltar que se modificou hipoteticamente o valor de uma constante física fundamental.
Apesar das indicações sobre como abordar a História e Filosofia da Ciência em aulas de Física Quântica, não se identificou um consenso sobre quais tópicos deveriam ser ensinados em aulas de Ensino Médio. Cuesta-Beltrán [16] enfatiza que uma das dificuldades do ensino de Física Quântica é que "não há concordância quanto ao conteúdo das aulas, nem quanto às abordagens interpretativas dos modelos científicos que tentam explicar algumas fenomenologias" [16, p. 151, tradução nossa]. O autor destaca que o tema mais frequente que aborda as propostas de ensino conceitual são os modelos atômicos. Entre as propostas de ensino com orientação em TICs (Tecnologias de Informação e Comunicação), o experimento de dupla fenda é o tema mais comum.

$\mathrm{Na}$ tentativa de mapear os tópicos que devem ser ministrados em aulas de Ensino Médio, KrijtenburgLewerissa, Pol, Brinkman e van Joolingen 15 realizaram um estudo, denominado estudo Delphi, com quarenta e oito professores universitários de diversas universidades holandesas, que se constituiu em entrevistas em que cada professor deveria indicar os temas que julgasse indispensáveis em uma sequência didática para Ensino Médio, e qual metodologia de ensino deveria ser utilizada. Quanto à atividade didática, o ponto mais recorrente foi a elucidação de que professores de Ensino Médio devem propiciar situações para uma verdadeira alfabetização científica. O segundo tema mais recorrente diz respeito à necessidade de um ensino que prepare os estudantes para questões sociais. Quanto aos tópicos de Física Quântica, o estudo Delphi mostrou que a maioria dos especialistas considera os seguintes tópicos essenciais:

1. Dualidade: A dualidade onda-partícula, o comportamento corpuscular da luz, o comprimento de onda de "de Broglie", o princípio da incerteza de Heisenberg, o experimento de dupla fenda e o efeito fotoelétrico.

2. Funções de onda: A função de onda, a probabilidade e o poço potencial.

3. Átomos: Níveis de energia, quantização, estrutura atômica, linhas espectrais, átomo de hidrogênio e tabela periódica [15, p. 16, tradução nossa].

Os autores ressaltam que essa lista não pode ser tomada como sendo os tópicos que indubitavelmente devem ser ministrados em uma sequência didática de Ensino Médio, por dois fatores: (1) o contexto de cada escola pode não permitir a ministração de determinados tópicos, por falta de tempo ou falta de conhecimentos prévios dos alunos para um bom entendimento de um dado tema; (2) estes tópicos variaram para cada entrevista. Se é modificada a quantidade de professores, ou se entrevistados professores de outras localidades, os assuntos podem receber diferentes níveis de importância, ou alguns assuntos muitas vezes não são lembrados. Nesse estudo, por exemplo, os entrevistados não deram grande importância ao tema das linhas 
espectrais, mas em outros estudos mencionados por Krijtenburg-Lewerissa et al. [15], o tema das linhas espectrais aparece como o mais relevante, juntando-se à ideia de modelos atômicos [16]. Contudo, apesar das variações, nota-se certa concordância acerca da inclusão de alguns tópicos no Ensino Médio, a saber: dualidade onda partícula, comportamento corpuscular da luz manifestado no efeito fotoelétrico (o efeito Compton sequer é citado), o comprimento de onda de "de Broglie", o experimento de fenda dupla e, por fim, o princípio de incerteza. Krijtenburg-Lewerissa et al. [15] enfatizam que estes temas são sempre lembrados pelos cientistas, independente da quantidade ou contexto das entrevistas, e, portanto, são relevantes para ministrações de Ensino Médio; demais tópicos devem ser ministrados conforme necessidade ou interesse do professor.

Stadermann, van den Berg e Goedhart 24] destacam que uma explicação razoável para a popularidade de tópicos como linhas espectrais e o efeito fotoelétrico é que esses fenômenos podem ser demonstrados em experimentos relativamente simples dentro dos meios disponíveis na maioria das escolas de Ensino Médio. Em uma área muita teórica como é a Física Quântica, os experimentos possíveis são considerados importantes para a compreensão dos alunos. Markin, Markina e Eilks 22 enfatizam que as aulas de ciências que incluem atividades práticas e demonstrações são muito mais motivadoras, divertidas e interessantes para os alunos em comparação às aulas baseadas apenas em conversas e mídias. Demonstrações com luz (mudanças de cor, dicroísmo, fluorescência são alguns dos assuntos abordados pelos autores) podem ser de particular interesse, pois fornecem resultados que podem ser facilmente observados. Defendem que os estudantes não possuem meios de visualizar aspectos da Física Quântica no dia a dia, por mais que a Quântica seja a base do desenvolvimento tecnológico atual, permitindo o uso de diversos aparelhos eletrônicos. Se o aluno não tiver meios de ver os assuntos estudados de maneira prática, esta defesa da Quântica se torna irrelevante para o aluno [24]. Para uma correta percepção da relevância do tema, então:

Eles devem experimentar instâncias de quantização em laboratório, realizando experimentos, ou experimentar isso através das instruções do curso, interpretando o que é explicado [19, p. 19, tradução nossa].

Neste sentido, Clavijo, Walteros e Cortés 21] buscam estimular nos estudantes uma "intuição quântica" a partir de um conhecimento quântico usando atividades experimentais como o espectro da luz visível e o experimento da polarização da luz, com o que propõem que os alunos podem deixar de lado ideias clássicas, adquirindo conceitos de estado, princípio de superposição e amplitude de probabilidade. Os autores realizaram uma série de atividades com fontes de luz, entendendo um feixe de luz como formado por um conjunto de fótons, mostrando assim ideias iniciais sobre o conceito de estado quântico. Para isso, utilizam, em um momento inicial, um feixe de luz branca e incidindo-o sobre um prisma, ao observar a decomposição da luz numa base arbitrária de seis estados, propiciam uma abordagem distinta da Óptica, enfatizando que cada estado de fóton de luz branca $\left|F_{B}\right\rangle$ pode ser escrito como uma combinação linear de conjunto de fótons para as demais cores, $|R\rangle,\left|A_{Z}\right\rangle,\left|V_{D}\right\rangle$, $\left|A_{M}\right\rangle,|L\rangle$ e $\left|V_{L}\right\rangle$ (roxo, azul, verde, amarelo, laranja e vermelho), de forma que $\left|F_{B}\right\rangle=\frac{1}{\sqrt{6}}\left(|R\rangle+\left|A_{Z}\right\rangle+\right.$ $\left.\left|V_{D}\right\rangle+\left|A_{M}\right\rangle+|L\rangle+\left|V_{L}\right\rangle\right)$. Assim, apresentaram um tópico simples, com uma formulação nova que permitiu o entendimento de algumas ideias básicas da Mecânica Quântica.

Também se percebeu a relevância dada por alguns autores com respeito à atividade didática, para que a obtenção de significados seja eficaz. Defendem que o professor crie um ambiente na sala de aula que propicie um espaço de máxima convivência, como condição à possibilidade de desenvolver a identidade de cada um de seus membros em harmonia e felicidade [4]. Estes autores destacam, em uma perspectiva baseada na epistemologia de Maturana, que para construir e contribuir para a "geração de um espaço de convivência, é necessário estar em aceitação do outro. Enquanto a emoção que especifica as ações científicas é a curiosidade e a paixão por explicar, a emoção que especifica as ações do professor é a paixão por se comunicar" [4, p. 62, tradução nossa].

\section{Entrevistas com Professores de Física}

Com base nos achados da revisão apresentada na seção precedente, julgamos importante fazer entrevistas semiestruturadas que foram realizadas junto aos cientistaseducadores de Física do Instituto de Física da UFRGS, escolhidos entre os que já haviam ministrado alguma disciplina relacionada à Física Quântica. Entrevistamos uma pequena quantidade de professores, de forma que os sete professores que participaram responderam tópicos diversificados que consideravam fundamental para compor um módulo de Física Quântica no Ensino Médio, com alguns tópicos que se repetiram ao longo das entrevistas, e ênfases distintas em formas de apresentar o conteúdo, porém com algumas semelhanças. Em resposta à pergunta guiadora, obtivemos a seguinte lista de tópicos sendo considerados mais relevantes de serem abordados em uma sequência didática para o Ensino Médio, apresentados na Tabela 1 .

Percebe-se que aparece em destaque o tema Interferência e Difração, que recebeu seis indicações. Apesar

\footnotetext{
5 Vale destacar que este tópico foi mencionado apenas quando se abordou na entrevista possíveis formas de tratar o misticismo quântico em sala de aula, então uma sugestão foi acrescentar como tópico a ser abordado a decoerência quântica. O surgimento deste tópico então não está diretamente ligado ao que se proponha na pergunta guiadora, mas influenciado pelo rumo que a entrevista tomou, quando se discutiu o tema do misticismo. Esta característica de flexibilidade é típica das entrevistas semiestruturadas.
} 
Tabela 1: Listagem de tópicos relevantes mencionados por especialistas do Instituto de Física da UFRGS para serem abordados no Ensino Médio.

\begin{tabular}{lc}
\hline $\begin{array}{l}\text { Tópicos de Física Quântica } \\
\text { considerados importantes }\end{array}$ & $\begin{array}{c}\text { Número de vezes } \\
\text { mencionado }\end{array}$ \\
\hline Interferência e Difração & 6 \\
Princípio de Incerteza & 3 \\
Fenda Dupla & 3 \\
Dualidade onda-partícula & 3 \\
Efeito Fotoelétrico & 3 \\
Fundamentos da Física Quântica & 3 \\
Radiação de Corpo Negro & 2 \\
Espectros de Emissão & 2 \\
Stern-Gerlach & 1 \\
Efeito Compton & 1 \\
Decoerência ${ }^{5}$ & 1 \\
\hline
\end{tabular}

Fonte: elaborado pelo primeiro autor (2019).

de essas indicações não precisarem ser seguidas à risca no que foi conduzido, entendemos que este tópico/tema não poderia ser omitido, dada à importância sobressaltada em comparação aos demais. Quanto à escolha de demais temas, nossa escolha foi livre, dando certa preferência para os temas que receberam três menções. Dada a relação direta entre experimentos de interferência e difração e a natureza dual da luz e da matéria, o tema dualidade onda-partícula acabou sendo selecionado para compor o MD. Frente à nossa preocupação em abordar aspectos da História e Epistemologia da Ciência, entendemos ser de extrema importância abordar o Efeito Fotoelétrico e a Radiação de Corpo Negro, tópicos marcantes para o início histórico da Física Quântica, de forma que incluímos estes temas em nossa atividade didática, citando principalmente o trabalho de Einstein e sua importância para esta área, que lhe rendeu o Prêmio Nobel.

Além disso, entendemos que uma abordagem histórica que permita elucidar a contribuição de Einstein à Física Quântica pode ser efetiva dado o grande reconhecimento deste cientista pelo grande público, inclusive pelos estudantes investigados, como revelam nossos dados coletados durante um estudo preliminar, com a aplicação de questionário [8]. E como Einstein é a figura mais (re)conhecida na ciência, e dados alguns entendimentos inadequados sobre suas crenças, elucidar em um trabalho de fronteira ao ensino [14 as crenças desse cientista e pesquisador, bem como de outros pesquisadores que foram sendo mencionados ao longo do módulo, pôde auxiliar para um entendimento mais amplo sobre a História e sobre a Epistemologia da Ciência, uma vez que, como menciona Jammer [37], as crenças religiosas de Einstein influenciaram grandemente sua visão de mundo e, por conseguinte, sua forma de encarar e fazer ciência.
Tabela 2: Formas de abordar os tópicos mencionados pelos especialistas entrevistados.

\begin{tabular}{lc}
\hline $\begin{array}{l}\text { Tópicos gerais para o Ensino } \\
\text { considerados importantes }\end{array}$ & $\begin{array}{c}\text { Número de vezes } \\
\text { mencionado }\end{array}$ \\
\hline $\begin{array}{l}\text { Abordagem Histórica e } \\
\text { Epistemológica }\end{array}$ & 3 \\
Ancomensurabilidade) & 2 \\
$\begin{array}{l}\text { Aplicações Tecnológicas } \\
\text { aula }\end{array}$ & 2 \\
$\begin{array}{l}\text { Convidar a escola para que os } \\
\text { alunos conheçam o Instituto de }\end{array}$ & 2 \\
Física & \\
Problemas do Cotidiano & 1 \\
Etimologia & 1 \\
Recursos Computacionais & 1 \\
\hline Fonte: elaborado pelo primeiro autor (2019).
\end{tabular}

Além destes tópicos, foi também selecionada a decoerência quântica como um tema promissor e relevante, apesar de mencionada uma única vez. Isso se deu pela possibilidade de o tema ser uma forma possível de lidar com o misticismo quântico, o que, semelhante ao estudo de Hilger e Moreira [7, foi identificado como concepção presente nos grupos em que se conduziria o MD.

Ainda quanto aos tópicos levantados pelos especialistas entrevistados, vale destacar que alguns mencionaram apenas, por exemplo, dois temas; isto não significa que não consideram outros temas como importantes, mas que consideraram que os temas mencionados por eles deviam receber mais atenção, ou ainda, que para um módulo curto, de poucos encontros, os temas mencionados deveriam receber especial atenção, por serem capazes de causar interesse nos alunos. Este foi o caso de entrevistas com dois professores que defenderam que fossem discutidos de alguma forma os Fundamentos de Física Quântica e debates relevantes relacionados, como o debate Einstein-Bohr em um começo de módulo didático.

Sobre a sequência em que estes tópicos podem ser apresentados, as respostas foram divergentes, sem alguma sequência sendo privilegiada. Escolhemos assim adotar uma sequência cronológica, o que é condizente com nossa proposta de abordagem histórica, introduzindo a Física Quântica com Planck, e o problema da radiação térmica de corpo negro, seguindo com a explicação do efeito fotoelétrico, posteriormente com interferência e difração, que abarca a dualidade ondapartícula. Ademais, alguns dos professores também fizeram menção a estratégias de ensino para apresentar os tópicos, o que é listado na Tabela 2

Destacamos a menção a uma abordagem Histórica e Epistemológica, mencionada três vezes. É preciso considerar que em nenhum momento os professores usaram o termo epistemologia, mas sim recomendaram 
abordagens que são entendidas por nós como sendo de cunho epistemológico, que nós reunimos nessa categoria. Entendemos que a discussão mencionada em três encontros de nossa aplicação sobre a importância de fazer a distinção entre o "mundo clássico" e o "mundo quântico", como colocou um dos professores entrevistados, reflete o aspecto da incomensurabilidade destacado na epistemologia, apesar de o professor não ter utilizado tal termo. Como discutido em Feyerabend [38], a Física Clássica e a Física Moderna constituem um dos poucos exemplos em Física de teorias incomensuráveis, pois há a criação de novos conceitos na segunda, que não estão presentes ou não fazem sentido para a primeira.

Apesar da dificuldade na comparação de teorias na epistemologia de Feyerabend, é clara a noção de incomensurabilidade e a formação de uma nova visão de mundo. Então, para os professores que mencionaram a importância de destacar a diferença entre Física Clássica e Física Quântica, ou Moderna de modo geral, há uma defesa indireta (não explícita) de uso de um discurso epistemológico, que pode ser bem explorado com o uso de um referencial epistemológico que aborde este tema.

Todas as estratégias mencionadas pelos professores, por não serem muitas, procuramos seguir durante a execução do MD, inclusive tendo a turma onde o módulo foi aplicado visitado o Instituto de Física da UFRGS, em decorrência do experimento de difração de elétrons, presente no Instituto, e recomendado por dois professores entrevistados, ser de manuseio extremamente difícil para ser levado à escola. Por uma questão de escolha, optamos por não seguir a recomendação pelo uso de recursos educacionais virtuais ou computacionais $\sqrt{6}$ dirigindo nosso foco para atividades experimentais simples e mais lúdicas. Também destacamos o uso da estratégia colocada como "etimologia", que foi mencionada por um professor, que defendeu ser fundamental o módulo ter uma aula, ou uma parcela de uma aula, dedicada ao estudo do que é quantização, o que é quantum, diferenciando aquilo que é quantizado daquilo que é contínuo. Isto foi feito em um primeiro encontro com a turma trabalhada.

Desta forma, transcrevemos as entrevistas com os sete professores e analisamo-las com o IRAMuTeQ. Por ser um software que permite a análise de matriz e análise textual, utilizamos seus recursos para análise de nossos textos obtidos através da transcrição das entrevistas. O recurso mais adequado escolhido foi a nuvem de palavras, que permite uma boa visualização e uma síntese das entrevistas, como apresentado na Figura 6

Destacamos que o software elimina automaticamente termos que não foram repetidos, ou que foram repetidos uma única vez, de forma que, para constituir

\footnotetext{
${ }_{6}$ Em alguns momentos usamos alguns vídeos disponíveis na rede, como em canais diversificados do YouTube, mas não contabilizamos isto como uso de recursos computacionais, pois não se trata de uso de simulações, que era o que o professor entrevistado sugeria na entrevista.
}

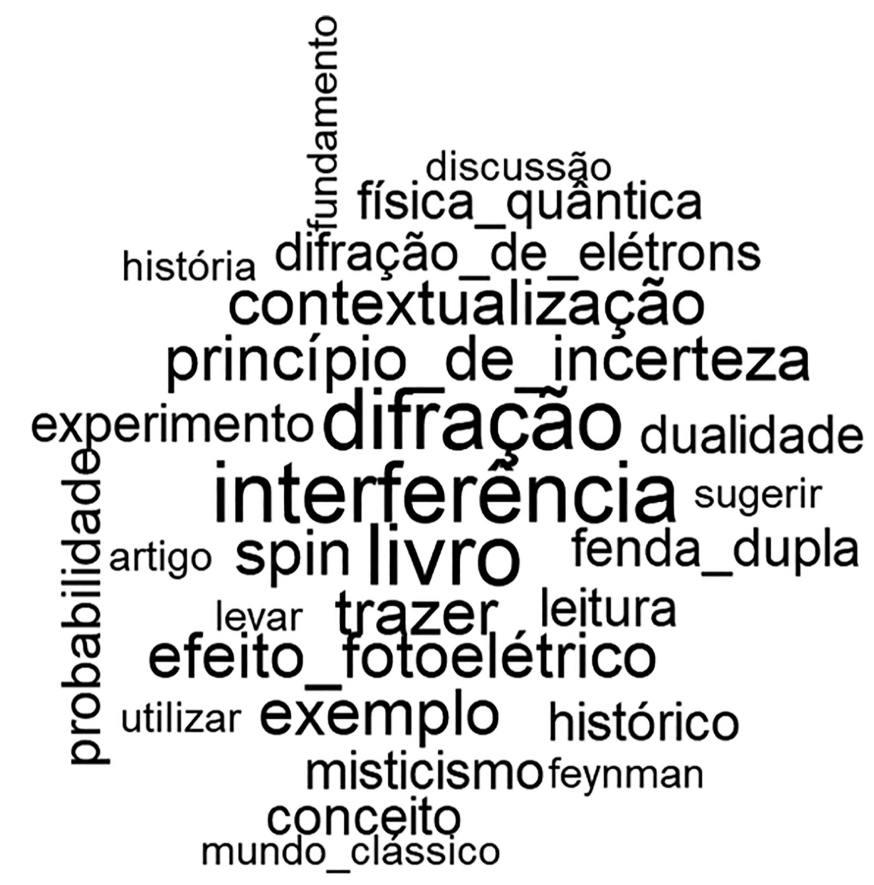

Figura 6: Nuvem de palavras a partir da transcrição das entrevistas com os professores especialistas. Fonte: elaborado pelo primeiro autor (2020).

a nuvem de palavras é necessário que uma palavra ou expressão tenha ocorrido no texto três vezes, no mínimo. Assim, termos como "radiação de corpo negro" ou "aplicações tecnológicas" não aparecem na nuvem de palavras. O programa também permite uma classificação de palavras, entre ativas e suplementares, que pode ser modificada antes da execução da nuvem. Termos como "professor" e "recomenda", foram classificados como suplementares, uma vez que não são conceitos chave nas entrevistas, mas figuravam como termos auxiliares na confecção do diário de bordo onde foram registradas as conversas das entrevistas. Por outro lado, termos relevantes são classificados como ativos, e a nuvem é feita tomando-se apenas estes termos. Como era esperado, "interferência e difração" aparecem como centrais (como mostrado também na Tabela 1) e em tamanho destacado, dada a repetição nas entrevistas. Termos como leitura, livro e artigo também podem ser visualizados, dada a recomendação pelos professores de leitura de diversas referências durante as entrevistas, algumas tendo sido adotadas.

Os termos "spin" e "misticismo" também figuram em nossa nuvem de palavras dado que algumas entrevistas seguiram rumos diferentes, sendo encaminhadas para questionamentos sobre estes termos. Por exemplo, um dos professores estava realizando à época da entrevista, pesquisas no ramo da spintrônica, de forma que questionamos se consideraria importante acrescentar o tema na sequência didática, dado que os alunos possivelmente estudaram números quânticos e número quântico de spin em aulas de Química. O mesmo questionamento foi feito 
a um professor que estava ministrando uma disciplina de magnetismo na pós-graduação e a um professor com doutorado em Física de Plasmas. Nos três casos, foi recomendado que o tema não fosse abordado em um módulo didático de Física Quântica, devido ao tema ser mais adequado a aulas de eletromagnetismo avançado ou por requerer um entendimento claro sobre momentum angular, que é um tópico pouco abordado em Ensino Médio.

Por fim, também se destaca a presença do termo misticismo na nuvem de palavras. Este tema surgiu em algumas entrevistas quando alguns professores questionaram sobre nossas propostas, em que abordamos os estudos de representação social e a presença de conceitos ligados ao misticismo nas representações. Em uma entrevista, em que o tema do misticismo foi abordado, foi sugerido abordar o tópico da decoerência quântica, uma sugestão que também seguimos na execução do módulo.

Assim, finalizamos a discussão deste breve estudo, que foi um estudo preliminar para a preparação e execução do MD. Destacamos que este estudo preliminar, inspirado em conselhos de Bruner [17] e em KrijtenburgLewerissa, Pol, Brinkman e van Joolingen [15], foi de extrema importância para o delineamento e execução do módulo, uma vez que os assuntos puderam ser escolhidos de forma mais bem estruturada e com uma boa fundamentação, bem como algumas sugestões de estratégias de ensino.

É importante relatar, contudo, que esta lista de conteúdos não deve ser tomada como uma receita, como um guia a ser indubitavelmente seguido. Os autores supracitados apontam que o professor precisa ter em mente que o contexto da escola deve ser sempre levado em conta, quaisquer que sejam os tópicos a serem ministrados e sobre a forma como serão ministrados. Em nosso caso, dada a dificuldade acentuada em matemática notada junto aos alunos em nossas observações que antecederam a aplicação do módulo, uma abordagem mais conceitual foi imprescindível, abordando apenas algumas expressões matemáticas, e apenas quando os conceitos foram bem adquiridos. Além disso, as respostas às entrevistas foram variadas para cada professor entrevistado, e as realizamos com um número reduzido de professores porque almejávamos obter indícios e sugestões, o que significa que a escolha sobre a ministração seguiu sendo inteiramente do pesquisador, mas entendemos que devemos estar sempre buscando nos basear na experiência dos especialistas, o que foi realizado.

\section{Breve Discussão Acerca do Módulo Didático (MD)}

Destacamos que uma explicação detalhada de nosso MD é apresentada na dissertação do primeiro autor [8]. Para fins deste artigo, torna-se inviável apresentar ao leitor todos os passos que foram seguidos, contudo, gostaríamos de apresentar alguns experimentos e discussões que auxiliaram na construção de uma aprendizagem conceitual pelos alunos e que, em certa medida, foram influenciados pelas entrevistas com professores de Física. Um experimento que queremos mencionar refere-se ao utilizado para abordar conceitualmente a relação entre energia e frequência, antes de ser introduzida a relação matemática $E=n h f$ (optamos por $f$ ao invés de $\nu$, para evitar complicações adicionais no entendimento da formulação matemática). Tratou-se de um experimento simples para o qual foi necessária uma fonte de tensão variável (utilizamos uma nossa, mas a escola possuía uma funcionando em perfeitas condições), cabos de conexão, um grafite (preferencialmente $0,5 \mathrm{~mm}$, pois o fenômeno não é tão visível para grafites $0,7 \mathrm{~mm}$ ou superior, ao menos nas faixas de tensão utilizadas) e um pote de vidro ou copo de béquer (disponíveis no laboratório do colégio). O experimento consistiu em fazer passar uma corrente pelo grafite, de forma que este, por efeito Joule dissipasse calor, inicialmente radiação na faixa do infravermelho. À medida que aumentamos os valores de tensão, o brilho aumentava, passando do vermelho, ao laranja, ao amarelo (claro) e por fim chegou a uma coloração muito clara quando estava prestes a se romper. Explicamos que o aumento do brilho representava um aumento de frequência, com um aumento de temperatura que é entendida como aumento da energia dissipada. Assim, dado que se aumentava a frequência e a energia na mesma proporção, o entendimento da expressão matemática $E=n h f$ pôde ser facilitado.

Mais especificamente, conforme apresentado na imagem da Figura 7] observa-se que para 3,15A e 8V, notávamos a coloração avermelhada, tendendo para o laranja quando a voltagem se aproximava de 9V, mantendo a corrente constante. Para 9V observa-se a cor laranja nitidamente. Acima de $10 \mathrm{~V}$ tornava-se amarelo claro, ficando cada vez mais claro ao se aproximar de $15 \mathrm{~V}$. Em $15 \mathrm{~V}$ o grafite rompia. Na terceira e última vez que fizemos o experimento o grafite não se rompeu, mas ficou curvo e incandescente, maleável pela alta temperatura, que possivelmente foi atingida de maneira menos abrupta que nas tentativas anteriores. Ainda assim, não passamos a voltagem de $15 \mathrm{~V}$ pela temperatura elevada que aquecia sobremaneira os cabos ligados à fonte, pelo risco de derreter o plástico desses cabos.

Outro experimento que queremos elucidar se refere ao experimento mencionado por alguns professores de Física em nossas entrevistas semiestruturadas. Por ser um experimento com partes instrumentais mais sensíveis, conforme pode ser visualizado na Figura 8. e possuindo apenas um modelo no Instituto de Física da UFRGS, de forma que não poderia ser levado até a escola, prosseguimos de maneira a organizar uma visita e conduzir a turma até a Instituição.7 A visita se deu no dia dezessete de outubro de 2019 e contou com a ajuda

\footnotetext{
7 É de se destacar que a visita à Universidade teve uma importância social para esses educandos, como dito, oriundos de um bairro pobre, afastado e de alta vulnerabilidade social de
} 


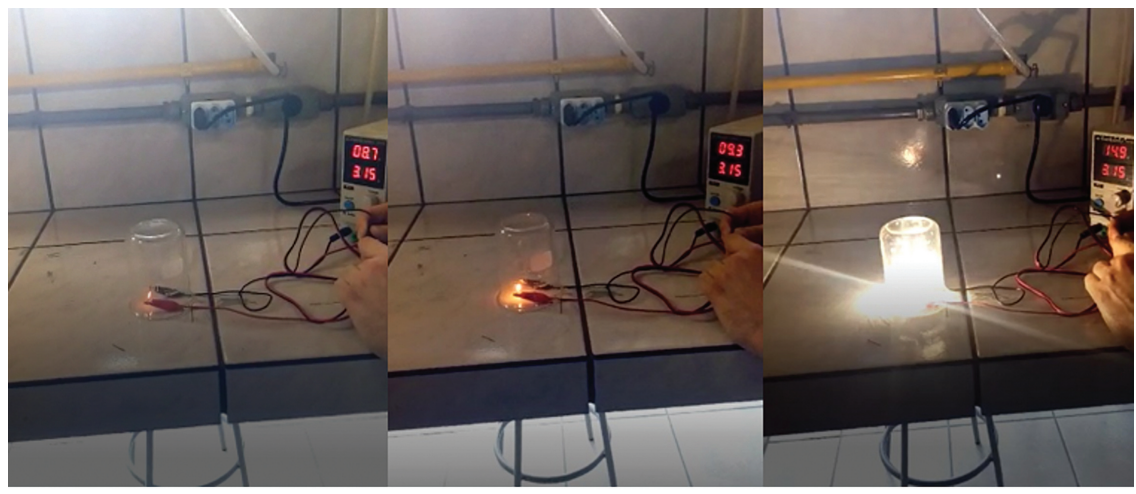

(a)

(b)

(c)

Figura 7: A sequência de imagens captura alguns momentos dos diferentes brilhos para o grafite, é possível ler a voltagem e a corrente na tela da fonte. Fonte: sequência de capturas de um vídeo pelos alunos, enviado ao professor (2019).

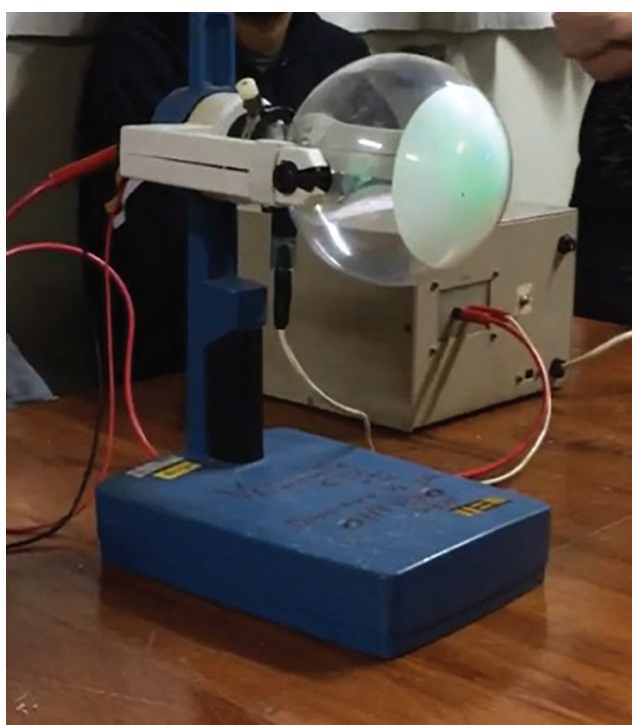

Figura 8: Experimento de Difração de elétrons do Instituto de Física. Fonte: captura de vídeo realizado pelos alunos e enviado ao professor (2019).

de técnicos do laboratório do Instituto de Física, tendo uma introdução pela segunda autora deste texto, seguida de uma explicação detalhada da difração de elétrons conduzida pelo primeiro autor com auxílio dos técnicos e profissionais especializados do departamento.

Conduzimos o experimento de difração de elétrons, para elucidar a dualidade onda-partícula e a hipótese de De Broglie. Iniciamos com uma breve retomada do que era difração e, após discutida e entendida a questão da dualidade onda-partícula, que já havia sido

uma cidade satélite de Porto Alegre. A maioria não conhecia a Universidade e vários desconheciam que se tratava de Instituição Federal, pública e gratuita, cujo acesso eles poderiam sonhar e lutar. Visitamos também, nessa oportunidade, o Museu de Paleontologia do Campus do Vale da UFRGS, espaço em que tiveram explicações sobre animais encontrados na Região Sul em camadas do período triássico (cerca de 230 milhões de anos). Foi para eles um dia memorável. mencionada em aulas anteriores, passamos à análise do que aconteceria com elétrons quando cruzassem uma fenda. A previsão da Física Clássica, se tomamos os elétrons como pequenas esferas, é o semelhante ao que se observa no tabuleiro de Galton, com a formação de uma curva gaussiana. Neste momento mostramos aos alunos o tabuleiro de Galton, que permite essa visualização do padrão clássico esperado.

Assim, destacamos que, se considerarmos os elétrons como pequenas esferas, eles deveriam seguir este padrão em um experimento de difração. Após a explicação do funcionamento do equipamento, visualizamos o padrão no anteparo após a difração de elétrons. Desligamos a luz da sala para visualizar melhor, mas vimos, ao invés de uma mancha verde contínua, uma figura com máximos e mínimos em torno de um pico central, de maneira muito semelhante ao que vimos para o laser e o fio de cabelo, clássico exemplo para evidenciar a difração de um feixe de luz ao passar por um fio de cabelo [39], experimento que havia sido realizado em momento anterior durante o MD. A luz verde no experimento de difração de elétrons se deve ao contato dos elétrons com o material que compõem o anteparo na parte de vidro do equipamento, como destacado no manual do equipamento fornecido pelos técnicos do departamento 8

Retomamos um nome que já havia sido mencionado em uma linha do tempo para a Física Quântica, que fora elaborada nas aulas iniciais: o nome de De Broglie. Ressaltamos a difração dos entes quânticos como elétrons, que, apesar de terem sido considerados sempre como partículas, também apresentam comportamento ondulatório. Enfatizamos assim a dualidade onda-partícula como acontecendo como todos os entes quânticos, isto é, tudo aquilo que é muito pequeno.

\footnotetext{
8 Roteiro elaborado e cedido pelo professor do Instituto de Física da UFRGS, José Henrique R. dos Santos. Disponível em: https: //www.ufrgs.br/labensif/experimentos/difracao-de-eletrons/ acessado em jan. 2021.
} 
Destacamos aqui, brevemente, que a difração não acontece com uma pessoa ao passar por uma porta, ou com uma bola ao passar por um obstáculo, uma vez que se perde o padrão quântico, ou mais precisamente, perde-se a coerência quântica. Enfatizamos, escrevendo no quadro, que esta perda da coerência quântica, perda do caráter probabilístico e, portanto, padrão de interferência e difração, é denominado de decoerência quântica. Ressaltamos que usar a Física Quântica para explicar situações do cotidiano é equivocado, porque essas situações são macroscópicas, visíveis, não são muito pequenas e, portanto, perde-se a coerência quântica. Há o surgimento deste fenômeno denominado decoerência quântica.

Além disso, a decoerência, também chamada de descoerência por alguns autores, por si só, não é exatamente algo novo, como destacado em Freire Jr., Pessoa Jr. e Bromberg [40]. A ideia básica está relacionada ao fato de que um sistema quântico que não esteja isolado do meioambiente terá propriedades completamente distintas daquelas apresentadas por um sistema isolado, perdendo o comportamento "dito quântico", que exibiria interferências, passando para um comportamento clássico, cujas propriedades como posição e trajetória estariam simultaneamente bem definidas. Algo interessante que essa discussão permitiu, foi o fato de poder explorar que essa interação com o ambiente e a perda do padrão quântico nos indica que não há exatamente um tamanho de corpos bem definido capaz de apresentar os efeitos quânticos, no sentido de que o efeito de difração de elétrons também foi identificado em moléculas grandes (por exemplo, como demonstram Fein et al. [41, em um experimento de superposição quântica de moléculas, consistindo de mais de 2000 átomos com massa em torno de $25000 \mathrm{Da}{ }^{9}$. Isto ilustra uma preconcepção no sentido de ser equivocada a afirmação de que ao estudarmos Física Quântica entramos em um mundo completamente novo, uma vez que as fronteiras para que se possa observar os fenômenos quânticos sequer são totalmente bem definidas, com a superposição quântica ainda sendo observada em moléculas massivas. De qualquer forma, enfatizamos que à medida que se aumentam as escalas de medida, os fenômenos quânticos ficam cada vez menos visíveis, menos perceptíveis, dado o aumento da descoerência, até a escala macroscópica, com situações do cotidiano, onde a interação com o ambiente é tão relevante que já não se observa qualquer coerência quântica.

\section{Conclusão}

A introdução de Física Moderna e Contemporânea no Ensino Médio não é uma discussão recente para a

\footnotetext{
9 Sendo esta uma unidade muito utilizada em Física atômica em química, o Dalton, ou simplesmente, unidade de massa atômica. Ela é definida como 1/12 da massa de um átomo de carbono-12 em seu estado fundamental.
}

comunidade de pesquisa em Ensino de Física. Contudo, poucos são os trabalhos que tratam como abordar este conteúdo de forma a tratar da História e Epistemologia da Ciência, além de que não há um consenso sobre quais tópicos ministrar, em que ordem e de que maneira. Para tentar amenizar estes problemas, trazemos com este artigo parte de um estudo maior conduzido durante uma investigação de um curso de mestrado acadêmico em Ensino de Física. Precisamente, consultamos a literatura referente ao tema para elucidar possibilidades para esta discussão. Com base em autores consultados em nossa revisão, foi preparado um Módulo didático, que foi precedido por uma pesquisa junto a professores especialistas para mapearmos de forma sintetizada conselhos para a execução do MD. O tema da difração e interferência apareceu como tendo importância indiscutível, como também foi destacado na literatura. Com sugestões dos professores entrevistados, foi possível realizar um bom número de atividades experimentais intercaladas com discussões dos episódios históricos que permearam o surgimento dos conceitos estudados durante as aulas, sobretudo as figuras de Planck e o surgimento da hipótese da quantização para a radiação de corpo negro e Einstein, por ser claramente identificada como a figura mais reconhecida pelos estudantes, além de seu papel fundamental para o estabelecimento da Física Quântica.

Em especial também destacamos um tópico que surgiu em nossas entrevistas, o tema da descoerência quântica, que pode ser abordada em sala de aula como resposta ao misticismo quântico. Faz-se importante destacar que estas entrevistas com professores especialistas foram conduzidas com um pequeno número de entrevistados, sendo, portanto, uma possibilidade conduzir um estudo semelhante com um número maior de professores, contudo serviu-nos de indicação para elaboração de nosso $\mathrm{MD}$, que privilegiou uma aprendizagem conceitual e discussões acerca da História e Epistemologia da Ciência.

Esperamos que o apresentado neste artigo possa servir de incentivo para que outros pesquisadores e, em especial professores da Educação Básica, avancem as pesquisas nesta temática e que possa ser uma via para introduzir não apenas conceitos de Física Quântica, mas igualmente aspectos da natureza da ciência articulados com a história do conhecimento científico, visando promover uma educação científica mais reflexiva.

\section{REFERÊNCIAS}

[1] F. Ostermann e M.A. Moreira, Investigações em Ensino de Ciências 5, 23 (2000).

[2] E.A. Terrazzan, Caderno Brasileiro de Ensino de Física 9, 209 (1992).

[3] L.F.M. Rosa, Explorando a inserção de tópicos de física quântica em uma escola estadual: um estudo sob a luz da perspectiva sociocultural. Dissertação de mestrado, Universidade Federal do Rio Grande do Sul, Porto Alegre (2019). 
[4] M.R. Otero, M.A. Fanaro e M. Arlego, Revista Electrónica de Investigación en Educación en Ciencias 4, 58 (2009).

[5] R. Scholz, S. Wessnigk e K. Weber, Eur. J. Phys. 41, 055304 (2020).

[6] W. Park, S. Yang e J. Song, Science \& Education 28, 1055 (2019).

[7] T.R Hilger e M.A. Moreira, Revista Electrónica de Investigación en Educación en Ciencias 8, 52 (2012).

[8] A.F. Hoernig, Física Quântica e História e Filosofia da Ciência: Conceitos, Vida, Crenças e Religiosidade como Motivadores na Aprendizagem de Física. Dissertação de Mestrado, Universidade Federal do Rio Grande do Sul, Porto Alegre (2020).

[9] S. Moscovici, Representações Sociais: investigações em Psicologia Social (Vozes, Petrópolis, 2015).

[10] L. Laudan, O Progresso e seus Problemas: rumo a uma teoria do crescimento científico (Editora Unesp, São Paulo, 2011).

[11] B. Billingsley e M. Nassaji, Sci \& Educ 28, 87 (2019).

[12] R. Carvalho, Stud of Sci Educ 11, 253 (2016).

[13] I. Lakatos, em: Scientific revolutions, organizado por I. Hacking (Oxford University Press, Oxford, 1983).

[14] K. Sorrell e E.H. Ecklund, Sociology of Religion: A Quarterly Review 80, 350 (2018).

[15] K. Krijtenburg-Lewerissa, H.J. Pol, A. Brinkman e W.R. Van Joolingen, International Journal of Science Education 41, 349 (2019).

[16] Y.J. Cuesta-Beltrán, Tecné Episteme y Didaxis: TED 44, 147 (2018).

[17] J. Bruner, O Processo da Educação (Edições 70, Lisboa, 1977).

[18] N.T. Massoni e M.A. Moreira, Pesquisa Qualitativa em educação em ciências: projetos, entrevistas, questionários, teoria fundamentada, redação científica (Editora Livraria da Física, São Paulo, 2017).

[19] M. Ayene, J. Krick, B. Damitie, A. Ingerman e B.A. Thacker, Int Journal of Sci and Math Educ 17, 1049 (2018).

[20] S.Y. Stevens, C. Delgado e J.S. Krajcik, Journal of Research in Science Teaching 47, 687 (2010).

[21] M.R. Clavijo, A. Walteros e C. Cortés, Tecné Episteme y Didaxis: TED 45, 191 (2019).

[22] A.V. Markin, N.E. Markina e I. Eilks, Proc. of SPIE 10336, 103360S (2017).

[23] M. Betz, I. Lima e G. Mussatto, Revista Brasileira de Ensino de Física 31, 3501 (2009).

[24] H.K.E. Stadermann, E. Van Den Berg e M.J. Goedhart, Physical Review Physics Education Research 15, 010130 (2019).

[25] F.S. Alemany, J.L.D. Blanco e J.M. Torregrosa, Revista Brasileira de Ensino de Física 35, 2404 (2013).

[26] K. Krijtenburg-Lewerissa, H.J. Pol, A. Brinkman e W.R. Van Joolingen, Physical Review Physics Education Research 13, 010109 (2017).

[27] E. Bertozzi, European Journal of Physics 34, 603 (2013).

[28] M.A. Asikainen e P.E. Hirvonen, Sci \& Educ 23, 1811 (2014).

[29] M.A. Fanaro e M. Elgue, Góndola, Enseñanza y Aprendizaje de las Ciencias 13, 272 (2018).
[30] A. Velentzas e K. Halkia, Res Sci Educ 41, 525 (2011).

[31] J. Heraud, P. Lautesse, F. Ferlin e H. Chabot, Sci \& Educ 26, 299 (2017).

[32] C.R. Pagliarini e M.J.P.M. Almeida, Ciênc. Educ. 22, 299 (2016).

[33] L. Ivanjek, P. Shaffer, M. Planinić e L. McDermott, Physical Review Physics Education Research 16, 010102 (2020).

[34] O. Levrini e P. Fantini, Sci \& Educ 22, 1895 (2013).

[35] G. Vergnaud, Rech. Didact. Math. 10, 133 (1990).

[36] P. Lautesse, A.V. Valls, F. Ferlin, J. Heraud e H. Chabot, Sci \& Educ 24, 937 (2015).

[37] M. Jammer, Einstein e a Religião (Contraponto, Rio de Janeiro, 2000).

[38] P.K. Feyerabend, A Ciência em uma Sociedade Livre (Editora Unesp, São Paulo, 2011).

[39] L.A. Souza, L. Silva, J.A.O. Huguenin e W.F. Balthazar, Revista Brasileira de Ensino de Física 37, 4311 (2015).

[40] O. Freire Jr, O. Pessoa Jr e J.L. Bromberg (orgs), Teoria Quântica: estudos históricos e implicaçôes culturais (EDUEPB, Campina Grande; Livraria da Física, São Paulo, 2010).

[41] Y.Y. Fein, P. Geyer, P. Zwick, F. Kialka, S. Pedalino, M. Mayor, S. Gerlich e M. Arndt, Nature Physics 15, $1242(2019)$. 